\title{
Spectroscopic Properties of Alumina Borosilicate Glassesw Alkaline Oxides Doped with Sm203 for Display Laser Emission
}

Nehal Elkhoshkhany

Jouf University

Samir Marzouk

Arab Academy of Science and Technology

Muhamed El Sherbiny

Alexandria University

Marihan Atef

Alexandria University

Mohammed Alqahtani

King Khalid University

Hamed Algarni

King Khalid University

Manuela Reben

AGH - University of Science and Technology

El Sayed Yousef ( $D$ omn_yousef2000@yahoo.com )

King Khalid University

\section{Research Article}

Keywords: Borosilicate glasses, UV-Vis-NIR spectra, Physical parameters, Spectroscopic properties, Laser emission.

Posted Date: July 12th, 2021

DOl: https://doi.org/10.21203/rs.3.rs-689110/v1

License: (c) (1) This work is licensed under a Creative Commons Attribution 4.0 International License.

Read Full License 


\section{Spectroscopic properties of alumina borosilicate glasses with alkaline oxides doped with $\mathrm{Sm}_{2} \mathrm{O}_{3}$ for display laser emission}

\section{N. Elkhoshkhany ${ }^{1,2}$, Samir Marzouk ${ }^{3}$, M. El-Sherbiny ${ }^{2}$, Marihan Atef ${ }^{2}$, Mohammed S. Alqahtani $^{4}$, H. Algarni ${ }^{5,6}$, Manuela Reben ${ }^{7}$, El Sayed Yousef ${ }^{5,6,8^{*}}$}

${ }^{1}$ Physics Dept., College of Arts and Sciences at Tabrjal, Jouf University, Al-Jouf, Saudi Arabia

${ }^{2}$ Department of Material Science, Institute of Graduate Studies and Researches, Alexandria University, 163 Horreya Avenue, Shatby, Alexandria 21526, Egypt

${ }^{3}$ Department of Basic and Applied Science, Faculty of Engineering and Technology, Arab Academy of Science and Technology, Cairo, Egypt

${ }^{4}$ Department of Radiological Sciences, College of Applied Medical Sciences, King Khalid University, Abha 61421, Saudi Arabia.

${ }^{5}$ Physics Dept., Faculty of Science, King Khalid University, Abha, P. O. Box 9004, Saudi Arabia

${ }^{6}$ Research Center for Advanced Materials Science (RCAMS), King Khalid University, Abha 61413, P. O. Box 9004, Saudi Arabi

${ }^{7}$ Faculty of Materials Science and Ceramics, AGH - University of Science and Technology, al. Mickiewicza 30, 30-059 Cracow, Poland.

${ }^{8}$ Physics Department, Faculty of science, Al Azhar University, Assiut Branch, Assiut, Egypt

\section{Abstract}

This research investigates the influence of the concentration of $\mathrm{Sm}_{+3}$ ions on the features of a new borosilicate glass system with the composition $50 \mathrm{~B}_{2} \mathrm{O}_{3}-14 \mathrm{SiO}_{2}-20 \mathrm{Li}_{2} \mathrm{O}-$ $15 \mathrm{Na}_{2} \mathrm{O}-1.0 \mathrm{Al}_{2} \mathrm{O}_{3}-\mathrm{x}\left(\mathrm{Sm}_{2} \mathrm{O}_{3}\right)$, where $\mathrm{x}=100,200,300,400$, and $500 \mathrm{ppm}$. The glasses are characterized by XRD, FTIR, UV- Vis- NIR, and photoluminescence spectra. The XRD results proved that all prepared glass has amorphous nature. Moreover, it was found that the value of density, $\rho$, and refractive index,n, increase with increasing of $\mathrm{Sm}^{+3}$ content. Otherwise, the value of molar volume, optical energy gap, and boron-boron distance decrease by increasing $\mathrm{sm}^{+3}$ concentration. The structure of glasses studied was investigated by computing Internuclear $\left(r_{i}\right)$, Polaron radius $\left(r_{p}\right)$, field strength $(F)$ and the deconvolution of FTIR spectra. Judd-Ofelt theory applied to clarify the structural changes and nature of the bonds of prepared glasses. Moreover, A spectroscopic quality factor, the branching ratio $(\beta r)$, and lifetime $(\tau)$ are calculated via the parameters of Judd-Ofelt. The color chromaticity of the present glasses evidenced that the emission was in the white-reddish orange region under 402nm excitation depended on the concentration of $\mathrm{Sm}^{3+}$ ions incorporated into the host glasses. From photoluminescence emission, stimulated emission cross-section, and CIE chromaticity leads to these glasses are promising for light-emitting diode (LED) as; laser material in a wide range.

Keywords: Borosilicate glasses; UV-Vis-NIR spectra; Physical parameters; Spectroscopic properties; Laser emission.

Corresponding authors: omn_yousef2000@yahoo.com 


\section{Introduction}

Borosilicate glass has attracted the researcher's attention due to its superior properties compared to ordinary glass. It has a very week thermal expansion coefficient equals to $3 \times$ $10^{-6} \mathrm{~K}^{-1}$ at $20{ }^{\circ} \mathrm{C}^{[1]}$ such glass doesn't suffer from thermal shock. It can be used in reflecting telescope manufacturing. ${ }^{[2]}$ Also, this glass helps to fabricate precise lenses. Borosilicate glass has a vital contribution to immobilizing and disposal of radioactive waste because it is distinguished by its chemical resistance. ${ }^{[3]}$ Borosilicate glass consists of different oxides such as $\mathrm{B}_{2} \mathrm{O}_{3}, \mathrm{SiO}_{2}, \mathrm{Na}_{2} \mathrm{O}, \mathrm{Li}_{2} \mathrm{O}$, and $\mathrm{AL}_{2} \mathrm{O}_{3}$. The mainly former of borosilicate glass is $\mathrm{B}_{2} \mathrm{O}_{3}$. Glass which is containing borates has special attention because of its promising linear and nonlinear optical properties ${ }^{[4]}$. The increase of $\mathrm{B}_{2} \mathrm{O}_{3}$ content enhances chemical resistance and improves transparency. Since borate glasses own high phonon energies which may hold back the efficiency of their luminescence during various relaxations ${ }^{[5]}$

The addition of silica to borate glass reduces the thermal expansion coefficient and enhances the melting point and the working point. The acid stability of the glass decreases as the silica concentration decreases. Another component of borosilicate glass is Alkali metal oxide. It cooperates with silica to reduce the melting temperature and enhancement of low thermal expansion. ${ }^{[6]}$ Alkali Metal oxide has an important role in the crystallization process, combining two metal oxide enhanced the resistance toward unwanted crystallization. [7] Therefore, alkaline earth cations can be added to the borate glass to upgrade their optical properties, impact the network connectivity, arranging of modifier cations and modify chain bonding in glasses by replacing the bridging oxygen with non-bridging oxygen ${ }^{[5]}$. $\mathrm{Li}^{+}$ions improve the acid-resistance of glass by forming bonds with glass networks ${ }^{[7]}$. Other oxides such as aluminum trioxide as a modifier of glass $\left(\mathrm{Al}_{2} \mathrm{O}_{3}\right)$, have an important role in the fluidity of the glass as increasing of alumina decreasing the fluidity of glass ${ }^{[7]}$. Alumina also enhances the temperature of glass processing ${ }^{[8]}$, enhancing the glasses' stability ${ }^{[9]}$, affect the lasing and thermo-mechanical properties of the products in which they have been associated ${ }^{[9]}$. Interestingly, borate glasses act as suitable host materials for exploring both the nature and structure of the luminescence and paramagnetic centers ${ }^{[10]}$.In the recent three decades, doped materials with trivalent rare earth $\left(\mathrm{RE}^{3+}\right)$ ions are extensively used for the upgrading of several optical devices, e.g. waveguides, up-conversion lasers, optical fibers, detection of infrared radiation, optical amplifiers, display devices, sensors, and light converters. ${ }^{[11-12]}$. The optically active f-f electronic transitions of lanthanides ions generate sharp emission lines when integrated into different glass matrices ${ }^{[11-5]}$. Owing to high thermal stability, promising optical, structural, and electrical properties low melting point, good $\mathrm{RE}^{3+}$ ion solubility, and 
high transparency, ${ }^{[11]}$. The importance of Glass containing $\mathrm{Sm}^{+3}$ is delivered from its visible emissions through different channels of emission ${ }^{[9]}$. The luminescence spectrum of $\mathrm{Sm}^{+3}$ ions in glasses and crystals shows distinct green, orange, and red emission bands, which refer to the ${ }^{4} \mathrm{G}_{5 / 2} \rightarrow{ }^{6} \mathrm{H}_{5 / 2},{ }^{4} \mathrm{G}_{5 / 2} \rightarrow{ }^{6} \mathrm{H}_{7 / 2}$, and ${ }^{4} \mathrm{G}_{5 / 2} \rightarrow{ }^{6} \mathrm{H}_{9 / 2}$ emission transitions, respectively that can be used in fluorescent display devices, visible lasers, new light sources, and UV sensor ${ }^{[10]}$. In this work, borosilicate glass which was doped with $\mathrm{Sm}^{3+}$ has been prepared with the chemical formula $\left(50 \mathrm{~B}_{2} \mathrm{O}_{3}-14 \mathrm{SiO}_{2}-20 \mathrm{Li}_{2} \mathrm{O}-15 \mathrm{Na}_{2} \mathrm{O}-1 \mathrm{Al}_{2} \mathrm{O}_{3}-\mathrm{xSm}_{2} \mathrm{O}_{3}\right)$, where $\mathrm{x}=100,200,300,400$, and $500 \mathrm{ppm}$. The objectives of this work are (i) To synthesis borosilicate glasses doped with $\mathrm{Sm}^{3+}$ with different concentration of $\mathrm{Sm}_{2} \mathrm{O}_{3}$ by usual melt quenching technique, (ii) To characterize the glass samples by XRD, FTIR, UV, and PL, (iii) To compute and measure the optical and physical parameters with different concentration of $\mathrm{Sm}_{2} \mathrm{O}_{3}$. (iv) To investigate optical properties which include the absorption and luminescence spectra. By the use of emission spectra of $\mathrm{Sm}^{3+}$ ions the color coordinates were evaluated and were presented in the CIE color diagram.

\section{Experimental}

The glass samples with composition of $50 \mathrm{~B}_{2} \mathrm{O}_{3}-14 \mathrm{SiO}_{2}-20 \mathrm{Li}_{2} \mathrm{O}-15 \mathrm{Na}_{2} \mathrm{O}-$ $1.0 \mathrm{Al}_{2} \mathrm{O}_{3}$ sample code (BSLNA0), $50 \mathrm{~B}_{2} \mathrm{O}_{3}-14 \mathrm{SiO}_{2}-20 \mathrm{Li}_{2} \mathrm{O}-15 \mathrm{Na}_{2} \mathrm{O}-1.0 \mathrm{Al}_{2} \mathrm{O}_{3}-100 \mathrm{ppm}$ $\mathrm{Sm}_{2} \mathrm{O}_{3}$, sample code (BSLNA1), $50 \mathrm{~B}_{2} \mathrm{O}_{3}-14 \mathrm{SiO}_{2}-20 \mathrm{Li}_{2} \mathrm{O}-15 \mathrm{Na}_{2} \mathrm{O}-1.0 \mathrm{Al}_{2} \mathrm{O}_{3}-200 \mathrm{ppm}$ $\mathrm{Sm}_{2} \mathrm{O}_{3}$, sample code (BSLNA2), $50 \mathrm{~B}_{2} \mathrm{O}_{3}-14 \mathrm{SiO}_{2}-20 \mathrm{Li}_{2} \mathrm{O}-15 \mathrm{Na}_{2} \mathrm{O}-1.0 \mathrm{Al}_{2} \mathrm{O}_{3}-300 \mathrm{ppm}$ $\mathrm{Sm}_{2} \mathrm{O}_{3}$, sample code (BSLNA3), $50 \mathrm{~B}_{2} \mathrm{O}_{3}-14 \mathrm{SiO}_{2}-20 \mathrm{Li}_{2} \mathrm{O}-15 \mathrm{Na}_{2} \mathrm{O}-1.0 \mathrm{Al}_{2} \mathrm{O}_{3}-400 \mathrm{ppm}$ $\mathrm{Sm}_{2} \mathrm{O}_{3}$, sample code (BSLNA4) and $50 \mathrm{~B}_{2} \mathrm{O}_{3}-14 \mathrm{SiO}_{2}-20 \mathrm{Li}_{2} \mathrm{O}-15 \mathrm{Na}_{2} \mathrm{O}-1.0 \mathrm{Al}_{2} \mathrm{O}_{3}-500 \mathrm{ppm}$ $\mathrm{Sm}_{2} \mathrm{O}_{3}$, sample code (BSLNA5). These glasses were synthesized and prepared by standard melt quenching technique. High-quality powders of lithium carbonate $\mathrm{Li}_{2} \mathrm{CO}_{3}(99.5 \%$, EUROMEDEX), sodium carbonate $\mathrm{Na}_{2} \mathrm{CO}_{3}$ (99\%, Chemajet), boric acid $\mathrm{H}_{3} \mathrm{BO}_{3}(99.98 \%$, Sigma-Aldrich), acid-washed quartz sands $\mathrm{SiO} 2$ (99.9 \%, Sigma-Aldrich), aluminum oxide $\mathrm{Al}_{2} \mathrm{O}_{3}$ (99\%, Sigma-Aldrich) and Samarium Oxide $\mathrm{Sm}_{2} \mathrm{O}_{3}$ (purity 99.9\%, Sigma-Aldrich) were weighed by using a digital balance and mixed well, then charged into platinum crucible followed by melting in an electric furnace at $1050{ }^{\circ} \mathrm{C}$ for 20 minutes. Then we poured melts onto a steel plate and annealed them in a furnace at $600{ }^{\circ} \mathrm{C}$ for $3 \mathrm{hr}$ to get rid of the thermal strains. The prepared glasses are named BSLNA0, BSLNA1, BSLNA2, BSLNA3, BSLNA4, and BSLNA5, respectively as found in Table 1. XRD was carried out to investigate the amorphous network of the prepared glass samples. BRUKER X-Ray Powder Diffraction 
system was used in this test. The range of investigation was ( 0-100) $2 \theta$ with a radiation source of $\mathrm{Cu}\left(\lambda=1.5406^{\circ} \mathrm{A}\right)$. An optical glass surface was obtained after polishing each sample surface with fine $\mathrm{Al}_{2} \mathrm{O}_{3}$ powder. The thickness of each sample was measured by a micrometer. Then the UV-vis-NIR absorption spectra were measured in the range of 200$2500 \mathrm{~nm}$ at ambient condition by spectrophotometer JASCO Corp, v-570, Rel-00 Japan with the double beam. The Photoluminescence spectra were recorded by using fluorescence spectrometer Ls 55 Perkin Elmer in the range of 300-900 $\mathrm{nm}$ at room temperature. FTIR was used to study the structural changes of each sample of glass after doping with different concentrations of $\mathrm{Sm}_{2} \mathrm{O}_{3}$. FTIR measurement in the range of $350-4000 \mathrm{~cm}^{-1}$ was occurred by BX Perkin Elmer equipment using $\mathrm{KBr}$ pellets.

\section{Results and Discussion}

Figure 1 demonstrates the XRD data of the prepared glass sample from BSLNA0 to BSLNA5. The XRD data confirmed the amorphous nature of glass by exhibiting broad diffused peaks. Moreover, no significant sharp peaks appeared in the data and the atoms of glass showed random distribution in the glass network, furthermore large variation in interatomic distances ${ }^{[9]}$.

The corresponding glass samples density were measured at ambient condition via Archimedes concept. The density of glass calculated by using Eq. [1],

$$
\rho=\frac{W_{\text {air }}}{W_{\text {air }}-W_{\text {liquid }}} \cdot \rho_{\text {liquid }} \quad\left(\mathrm{g} / \mathrm{cm}^{3}\right)^{[13]}
$$

Where, $\rho$, is a glass sample density $\left(\mathrm{g} / \mathrm{cm}^{3}\right), W_{\text {air }}$ is the weight of prepared glass in the air, $W$ liquid is the weight of glass in toluene and $\rho_{\text {liquid }}$ is a density of toluene $\left(0.864 \mathrm{~g} / \mathrm{cm}^{3}\right)$. The molar volume of glass samples was obtained by implementing the Eq. [2],

$$
\mathrm{V}_{\mathrm{m}}=\frac{M_{\text {wt sample }}}{\rho_{\text {sample }}} \quad\left(\mathrm{cm}^{3} / \mathrm{mol}\right)^{[13]}
$$

Since $\mathrm{V}_{\mathrm{m}}$ is the molar volume of the glass sample $\left(\mathrm{cm}^{3} / \mathrm{mol}\right)$ and $\mathrm{M}_{\mathrm{wt}}$ is the molecular weight of the sample. The $\mathrm{M}_{\mathrm{wt}}$ of the sample ( $\mathrm{g} / \mathrm{mol}$ ) could be obtained by Eq. [3], as well as oxygen packing density (OPD) (g.atom/L) could be obtained by applying for the Eq. [4],

$\mathrm{M}_{\mathrm{wt}}=\frac{50 \mathrm{~B}_{2} \mathrm{O}_{3}+14 \mathrm{SiO}_{2}+20 \mathrm{Li}_{2} \mathrm{O}+15 \mathrm{Na}_{2} \mathrm{O}+1 \mathrm{Al}_{2} \mathrm{O}_{3}+\mathrm{xSm} \mathrm{S}_{2} \mathrm{O}_{3}}{100} \quad(\mathrm{~g} / \mathrm{mol})$ 
Since, $\mathrm{C}$, is the oxygen atoms number which is existing in the structure of each glass sample. As found in Table 2, the density of glass samples was enhanced from 2.397 to $2.625 \mathrm{~g} / \mathrm{cm}^{3}$ by increasing the $\mathrm{Sm}_{2} \mathrm{O}_{3}$ concentration from 0 to $500 \mathrm{ppm}$. The increase in density as a result of increasing OPD from 78.3 to $85.61 \mathrm{~g}$.atom/L. Thus, the glass samples become denser and more compact ${ }^{[14]}$, another factor that increased the density of glass samples is the alteration of $\left[\mathrm{BO}_{3}\right]^{-3}$ triangles into $\left[\mathrm{BO}_{4}\right]^{-4}$ tetrahedral by the gradual increase of $\mathrm{Sm}^{3+}$ ions in glass samples. ${ }^{[15]}$

As a result of $\mathrm{Sm}_{2} \mathrm{O}_{3}$ concentration increasing in glass sample, the molar volume decreased from 27.58 to $25.24\left(\mathrm{~cm}^{3} / \mathrm{mol}\right)$, we ascribed this observation due to the decrease which occurs for both interatomic distances and the length of bonds between doped glass atoms. Such results enhanced the compactness of the structure. ${ }^{[9]}$ The average boron-boron separation is also calculated by Eq. 5 to clarify the effect of modifier concentration on the glass system.

$d^{\langle B-B\rangle}=\left(V_{M}^{B} / N_{A}\right)^{1 / 3}$

where;

$V_{M}^{B}=V_{M} /\left(1-X_{B}\right)$

Where $V_{M}^{B}$ and $X_{B}$ is molar volume and mole fraction of $\mathrm{B}_{2} \mathrm{O}_{3}$ respectively.

In the present work, by increasing $\mathrm{Sm}_{2} \mathrm{O}_{3}$ concentration, the boron-boron separation, $d^{\langle B-B\rangle}$, value decreased as shown in Table 2. Noticeably, the previous results confirmed that, by increasing the concentration of $\operatorname{Sm}_{2} \mathrm{O}_{3}$, the molar volume and the interatomic spacing decrease which enhanced the compactness of glass. ${ }^{[9]}$.

Ultraviolet-visible-near infra-red (UV-vis-NIR) optical absorption of $\mathrm{Sm}^{3+}$-doped BSLNA at ambient condition shows nine absorption peaks as shown in Fig. 2. These peaks result from electronic transitions from the ${ }^{6} \mathrm{H}_{5 / 2}$ level to the further excited states of the $\mathrm{Sm}^{3+}$ ion. These absorption peaks appear at $435,484,950,1094,1253,1402,1505,1536$, and $1563 \mathrm{~nm}$ due to transitions ${ }^{6} \mathrm{H}_{5 / 2}$ to ${ }^{4} \mathrm{~F}_{7 / 2},{ }^{4} \mathrm{I}_{13 / 2},{ }^{6} \mathrm{~F}_{11 / 2},{ }^{4} \mathrm{~F}_{9 / 2},{ }^{6} \mathrm{~F}_{7 / 2},{ }^{6} \mathrm{~F}_{5 / 2},{ }^{6} \mathrm{~F}_{3 / 2},{ }^{6} \mathrm{H}_{15 / 2}$ and ${ }^{6} \mathrm{~F}_{1 / 2}$ respectively ${ }^{[16-19]}$. The value of indirect optical band gap, $E_{o p t}^{i n}$, of prepared glasses can be calculated from the following Eq. [6] ${ }^{[20]}$.

$\boldsymbol{\alpha}(\mathrm{v})=\frac{\alpha_{\mathrm{o}}\left(\mathrm{h} v-E_{o p t}^{i n}\right)^{\mathrm{m}}}{\mathrm{hv}}$ 
Where, $\alpha(v)$, is the optical absorption coefficient ${ }^{[22]}$. By employing the Eq. [7] absorption coefficient $(\alpha)$ can be calculated by Eq. [7]. ${ }^{[12]}$

$$
[7] \alpha(\mathrm{v})=\frac{1}{\mathrm{t}} \ln \frac{\mathrm{I}_{\mathrm{o}}}{\mathrm{I}_{\mathrm{t}}}
$$

The thickness of the glass samples is $t$ and the intensity of incident light is $I_{0}$, while the intensity of transmitted light is $I_{t}$. Light energy is $h v, \alpha_{0}$ is an energy-independent constant, $\mathrm{m}=2$ for the allowed indirect transition. Tauc's plot is shown in Fig 3. for indirectly allowed transitions. $E_{o p t}^{\text {in }}$ can be determined by deriving a linear portion of the curve to the $\mathrm{X}_{\text {axis }}$ at $\mathrm{Y}_{\mathrm{axis}}=0$. The values are monitored and found in Table 3. As is evident, $E_{\text {opt }}^{\text {in }}$, values were reduced from 3.61 to $2.0 \mathrm{eV}$ by increasing $\mathrm{Sm}_{2} \mathrm{O}_{3}$ concentration from 0 to $500 \mathrm{ppm}{ }^{\text {[20] }}$. If the oxygen bonding (BO) in the glass network, such as non-bridging oxygen forming (NBO), modifies the absorption properties, an increase in the concentration of $\mathrm{Sm}^{3+}$ ions can occur. It leads to a high non-bridging oxygen concentration owing to a change in the binding of oxygen. Concerning this increase in the concentration of $\mathrm{Sm}^{3+}$ ions, the degree of electron delocalization in the compactness of the glasses is decreased, decreasing the optical energy band difference. This describes why, when $\mathrm{Sm}_{2} \mathrm{O}_{3}$ content increases, the optical band distance decreases. Where, $\Delta \mathrm{E}$, an Urbach energy can be represented as the width of a localized state in the typically forbidden gap. Increasing $\Delta \mathrm{E}$ values indicate a higher tendency of the disturbance system to change weak bonds into defects. It is calculated by Eq. [8] ${ }^{[12]}$.

$\alpha(v)=\alpha_{o} \exp \left(\frac{h v}{\Delta E}\right)$

Where $\alpha(v)$ is the optical absorption coefficient and $\alpha_{0}$ is constant ${ }^{[13-20]}$. The values of $\Delta \mathrm{E}$ can be computed from $\ln (\alpha)$ versus photon energy, $\Delta \mathrm{E}$, see Fig. (4), which can be affected by extensions of the valence and conduction bands to the bandgap region.

The glass samples which doped with a different concentration of $\mathrm{Sm}_{2} \mathrm{O}_{3}$ exhibited increasing $\Delta \mathrm{E}$ values from 0.36 to $1.37 \mathrm{eV}$ by increasing the concentration of $\mathrm{Sm}_{2} \mathrm{O}_{3}$. The present glass sample doped by 500ppm of $\mathrm{Sm}_{2} \mathrm{O}_{3}$ showed $\Delta \mathrm{E}$ equaled $1.37 \mathrm{eV}$, higher than the un-doped glass sample which exhibited $\Delta \mathrm{E}$ equaled to $0.36 \mathrm{eV}$. A higher concentration of $\mathrm{Sm}_{2} \mathrm{O}_{3}$ increases the degree of disordered which results in higher values of $\Delta \mathrm{E}$, also the degree of disordered ${ }^{[13]}$. 
The physical parameters such as; $r_{i}, r_{p}, F, n, R_{m}$, and $\alpha_{\mathrm{m}}$ confirm the glass structure which is determined by the following Eq. [8],[9],[10],[11] $]^{[12-20]}$ Concentration of ions $\quad N=R E \operatorname{mol} \% \cdot \frac{N_{A} * \rho}{\text { glass average molecular } w t}$

Internuclear distance $\left(r_{i}\right)=\left(\frac{1}{N}\right)^{1 / 3}$

Polaron radius $\left(r_{p}\right)=\frac{1}{2}\left(\frac{\pi}{6 N}\right)^{1 / 3}$

Field strength $(F)=\frac{Z}{r_{p}^{2}}$

Where $(N)$ concentration of $\mathrm{Sm}^{3+}$ ions, $N_{A}$ is Avogadro's number, $\rho$ is the density of glass sample and $Z$ is the atomic mass of samarium ion $Z_{\mathrm{Sm}}=150.36 \mathrm{~g} \cdot \mathrm{mo}{ }^{[22]},\left(r_{i}\right)$ mean distance between the $\mathrm{Sm}^{3+}$ ions, $\left(r_{p}\right)$ polaron radius and $(F)$ field strength of $\mathrm{Sm}-\mathrm{O}$ bond in doped BSLNA glass. The values have been calculated and placed in Table 4.

As is clear of calculated values, $r_{i}$ and, $r_{p}$, values reduce with increasing $\mathrm{Sm}^{3+}$ ions. Consequently, the strength of the Sm-O bond increases, so the field strength (F) around $\mathrm{Sm}^{3+}$ ions becomes stronger. The combining between these obtained values and the density results confirms the compactness of glass structure with addition $\mathrm{Sm}^{3+}$ ions consequently, decreasing in the degree of delocalization of electrons occurs, due to increase in the compactness of glass and then increases the donor centers in the glass matrix and as a result, optical energy band gap decreases. ${ }^{[20]}$

The refractive index, $\mathrm{n}$, is one of the most significant properties in optical glasses ${ }^{[21]}$. The refractive index values of prepared glass samples were calculated by using Dimitrov and Sakka relation as shown in equation [13] ${ }^{[22]}$ and obtained in Table 5.

$\frac{\left(\mathrm{n}^{2}-1\right)}{\left(\mathrm{n}^{2}+2\right)}=1-\sqrt{\frac{E_{o p t}^{i n}}{20}}$

The, $n$, value increases from 2.2497 to 2.736 with the concentration of $\mathrm{Sm}^{3+}$ ions increase from 0 to 500ppm in prepared glasses. The value of $\mathrm{n}$ depends on ion polarization, electron density, and molar masses. The improvement in the refractive index is due to strong polarizable nonbridging oxygen (NBOs) generation in the glass network. Non-bridging oxygen formation provides greater polarizability over the covalent oxygen bridging bonds by providing a higher refractive index. 
The nonlinear response of the materials depends on polarizability. The electronic polarization of the materials causes the optical non-linearity upon exposure to intense light beams ${ }^{[22]}$. Polarizability is correlated to physical and chemical properties such as optical UV absorption of metal ions and electro-optical effect ${ }^{[23]}$. The molar refraction is proportionate to molar polarizability, which is associated with the glass sample structure.

Molar refraction $\left(R_{m}, \mathrm{~cm}^{3} \mathrm{~mol}^{-1}\right)$ is calculated by applying the following Lorentz-Lorenz Eq. 14:

$R_{m}=\frac{\mathrm{n}^{2}-1}{\mathrm{n}^{2}+2} V_{m}$

Molar polarizability $(\alpha \mathrm{m})$ can be calculated by the Eq. [15]:

$\alpha_{m}=\frac{R_{m}}{2.52}$

The values of polarizability $\left(\alpha_{\mathrm{m}}\right)$ and molar refraction $\left(\mathrm{R}_{\mathrm{m}}\right)$ for samarium doped glass samples are listed in Table 3. Also the dielectric constant $(\varepsilon)$ and refraction loss $\left(\mathrm{R}_{\mathrm{L}}\right)$ is computed by employing the following equations: ${ }^{33]}$

$\varepsilon=n^{2}$

$R_{L}=\left(\frac{\mathrm{n}-1}{\mathrm{n}+1}\right)^{2}$

The increase in the, $R_{m}, \alpha_{m}, \varepsilon$ and $R_{L}$ be attributed to the increase of the (NBO) in the glasses network structure with increasing $\mathrm{Sm}^{3+}$ ions.

Judd-Ofelt concept has been used to get more information about glass structure and also depends on host material ${ }^{[13]}$. The parameters of Judd-Ofelt was detected by taking the least square fitting between the calculated and experimental oscillator strength ( $f_{\text {cal }}$ to $\left.f_{\exp }\right)$ and recorded in Table7. Fexp of the absorption band was calculated from the Eq. [18]

$\mathrm{F}_{\exp }=\frac{2.303 \mathrm{mc}^{2}}{{\mathrm{~N} \pi \mathrm{e}^{2}}^{2}} \int \varepsilon(\mathrm{v}) \mathrm{du} \quad[13]$

where $\mathrm{m}$ and e are the electron's mass and charge, respectively. $\mathrm{N}$ is Avogadro's constant, $\mathrm{c}$ is light velocity, the molar absorptivity $\left(\mathrm{cm}^{-1}\right)$ is symbolized by $\varepsilon(v)$, and $\int \varepsilon(v) d v$ is the part which is located under the curve of absorption. $F_{c a l}$ was determined from the Eq. [19] ${ }^{[13]}$

$\mathrm{F}_{\mathrm{cal}}=\frac{8 \pi^{2} \mathrm{mcv}}{3 \mathrm{~h}(2 \mathrm{~J}+1)} \frac{\left(\mathrm{n}^{2}+2\right)^{2}}{9 \mathrm{n}} * \sum_{\lambda=2,4,6} \Omega_{\lambda}\left(\phi \mathrm{J}\left\|\mathrm{U}^{\lambda}\right\| \phi^{\prime} \mathrm{J}^{\prime}\right)^{2}$ 
where $\mathrm{m}$ is the electron mass, the wavenumber $\left(\mathrm{cm}^{-1}\right)$ is symbolized by $v, \mathrm{c}$ is light velocity, $\mathrm{h}$ is Plank's constant, the refractive index is symbolized by $\mathrm{n}$, the Lorentz local electric field correction is equal $\left(n^{2}+2\right)^{2} / 9 n$, Judd-Ofelt parameters are symbolized by $\Omega \lambda$ where $(\lambda=2,4,6)$, the ground state angular momentum is symbolized by $\mathrm{J}$, the excited state is symbolized by $\phi$ $\wedge^{\prime} \mathrm{J}$ ', the ground state is symbolized by $\phi \mathrm{J}$, and $\left\|\mathrm{U}^{\lambda}\right\|^{2}$ refers to squared doubly reduced matrix elements of the tensor operator. Parameters of Judd-Ofelt are significant to know more around rare earth environments, the Internal structure of glass, the nature of bonds and tell us more about the relation between $\mathrm{Sm}^{3+}$ ions and the host material ${ }^{[13]} . \Omega 2$ symbolizes changes in internal structure, the nature of bonds, asymmetric, and covalent bonds between rare earth ions and surrounding ligands ${ }^{[13]} . \Omega 4$ and $\Omega 6$ related to the rigidity and viscosity of prepared glass ${ }^{[13]}$. The higher values of $\Omega 4$ and $\Omega 6$ in our glass system confirm the high rigidity and high viscosity of this glass ${ }^{[13]}$. By calculating the ratio between $\Omega 4$ and $\Omega 6$ parameters the spectroscopic quality factor $\mathrm{X}$ will be obtained, which tells us about the quality of prepared glass samples. In our glass system X-factor $(>1)$ confirms the high quality and stability of this glass, therefore, it can be used in optical devices development ${ }^{[13]}$. It is observed from Table (7) that the parameters of Judd-Ofelt show the trend as $\Omega 4>\Omega 2>\Omega 6$ for all prepared glass samples except the BSLNA4 sample it shows the trend $\Omega 4>\Omega 6>\Omega 2$. The same trend has been observed in the reported $\mathrm{Sm}^{+3}$ doped borate glasses ${ }^{[11]}$. In the two upper cases, the higher magnitudes of $\Omega 4$ confirm the high rigidity of prepared glass samples ${ }^{[13]}$. Lower magnitudes of $\Omega 2$ are due to distortion that results from the change in structure due to the large size of modifier and strong Sm-O bond ${ }^{[13]}$ which confirmed the high degree of symmetry and strength of ionic bond nature around the $\mathrm{Sm}^{3+}$ ions ${ }^{[13}$. Also, we calculated the root mean square (r.m.s) by equation [20]. To estimate the quality of the fit between the two oscillator strengths $\mathrm{f}_{\text {cal }}$ and $\mathrm{f}_{\text {exp. }}$.

r.m.s. $=\left(\sum_{\mathrm{p}} \frac{\left(\mathrm{f}_{\mathrm{cal}}-\mathrm{f}_{\mathrm{exp}}\right)^{2}}{\mathrm{p}-3}\right)^{1 / 2}$

Where $\mathrm{p}$ is the number of observed transitions on the absorption spectrum.

The lower values of r.m.s. Is evidence that fitting quality Table (5).

Branching ratio describes the probability of stimulated emission for a specific transition, it is a significant factor in laser manufacturer and it has been used to predict the intensities of radiative emission lines that result from an excited state ${ }^{[13]}$. $\beta r$ is calculated from the equation [21] ${ }^{[13]}$

$\beta_{\mathrm{r}}=\frac{\mathrm{A}_{\mathrm{Rad}}}{\mathrm{A}_{\mathrm{T}}}$ 
Where $A_{R a d}$ is the probability of transitions from excited $b^{\prime}$ to lower state aJ for electric dipole spontaneous emission and it is obtained from Eq. [22], $\mathrm{A}_{\mathrm{T}}$ symbolizes to total possibilities of all transitions. The transition which $\beta \mathrm{r} \geq 0.50$ is extra distinct for laser radiation [13]. From table 8, it is observed that ${ }^{6} \mathrm{H}_{5 / 2} \rightarrow{ }^{6} \mathrm{~F}_{1 / 2}$ emission, shows the highest values of branching ratio $(\beta r \geq 0.50)$ so, it can be used for a laser manufacturer. Radiative lifetime $\tau$ is not affected by phonon energy of the host matrix but it primarily depends on the total probability of spontaneous transition ${ }^{[13]}$.

$A_{R}=\frac{64 \pi^{4} v^{3} n\left(n^{2}+2\right)^{2} e^{2}}{27 h C^{2}(2 J+1)}\left[\sum_{\lambda=2,4,6} \Omega_{\lambda}\left(a J\left\|U^{\lambda}\right\| u J^{\prime}\right)^{2}\right]$

The absorption cross-section $\sigma_{a b}$ of $\mathrm{Sm}^{+3}$ doped BSLNA glass obtained by the equation $[23]^{[13]}$

$\sigma_{\mathrm{AB}}(\lambda)=\frac{2.303 \mathrm{OD}(\lambda)}{\mathrm{NL}}$

The cross-section absorbance is symbolized by $\sigma_{\mathrm{ab}}, \mathrm{OD}(\lambda)=\log \mathrm{Io} / \mathrm{I}$, which refers to the experimental absorption spectrum optical density, $\mathrm{N}$ refers to $\left(\mathrm{Sm}^{3+}\right.$ ions) concentration, and the sample thickness is symbolized by L. The emission cross-section $\sigma_{\mathrm{EM}} \mathrm{of} \mathrm{Sm}^{+3}$ doped BSLNA glass is obtained by the equation [24] ${ }^{[13]}$

$\sigma_{\mathrm{EM}}(\lambda)=\sigma_{\mathrm{AB}}(\lambda) \frac{\mathrm{Z}_{\mathrm{L}}}{\mathrm{Z}_{\mathrm{u}}} \mathrm{e}^{\left(\frac{\mathrm{E}_{\mathrm{ZL}-\mathrm{hc} \lambda^{-1}}}{\mathrm{~K}_{\mathrm{B}} \mathrm{T}}\right)}$

$Z_{\mathrm{u}}$ refers to partition functions for upper levels, $\mathrm{Z}_{\mathrm{L}}$ refers to partition functions for the lower levels, which are involved in the considered optical transition, EZL is zero-line energy for the movement that occurs between the lower Stark sublevels of both emitting and receiving multiples $^{[13]}$. Figure 5 shows the cross-sections of both absorption and emission. The $\sigma_{\mathrm{EM}}$ values for $\mathrm{Sm}^{+3}$-doped glass in the range of $100 \mathrm{ppm}$ to $500 \mathrm{ppm}$ were about $2.9 \times 10^{-21}, 2.17 \times$ $10^{-21}, 1.92 \times 10^{-21}, 3.24 \times 10^{-21}, 2.25 \times 10^{-21}$, respectively. Also, the gain cross-section was obtained from the absorption and emission cross-section by the Eq. [25] ${ }^{[13]}$.

$\sigma_{\text {gain }}=P \sigma_{E M}(\lambda)-(1-P) \sigma_{A B}(\lambda)$

Where $\sigma_{\text {gain, }} \sigma_{\mathrm{EM}}$, and $\sigma_{\mathrm{AB}}$ are cross-sections of gain, for both emission and absorption. Finally, the population inversion is symbolized by P. As shown in figure 10, at a certain wavelength the gain cross-section has been determined for $(\mathrm{P}=0,0.1,0.2,0.3,0.4, \ldots, 1)$. It 
was observed from Fig. 6 that gain coefficients at $1226 \mathrm{~nm}$ were $5.01 \times 10^{-21}, 3.7 \times 10^{-21}$, $3.2 \times 10^{-21}, 3.4 \times 10^{-21}, 3.7 \times 10^{-21}$. The prepared glasses are promising for potential photonic application due to high values of gain coefficient and stimulated emission cross-section.

The measuring of the emission spectra of prepared glass at started by indicating the excitation wavelength $402 \mathrm{~nm}$ as shown in Figure.7. The spectra of emission of $\mathrm{Sm}^{3+}$ doped BSLNA glass show three important peaks centered at 562, 600, and $647 \mathrm{~nm}$, due to transition from ${ }^{4} \mathrm{G}_{5 / 2} \rightarrow{ }^{6} \mathrm{H}_{5 / 2},{ }^{6} \mathrm{H}_{7 / 2}$, and ${ }^{6} \mathrm{H}_{9 / 2}$ transitions of $\mathrm{Sm}^{3+}$ ions, respectively ${ }^{[12,27]}$. The emission line centered at $600 \mathrm{~nm}\left({ }^{4} \mathrm{G}_{5 / 2} \rightarrow{ }^{6} \mathrm{H}_{7 / 2}\right)$ is the highest intense from all BSLNA glasses doped with $\mathrm{Sm}^{3+}$ ions which give orange emission ${ }^{[12]}$ and ${ }^{4} \mathrm{G}_{5 / 2}-{ }^{6} \mathrm{H}_{9 / 2} \quad(647 \mathrm{~nm})$ transition gives red emission ${ }^{[12]}$ and shows moderate intensity, the transition at $562 \mathrm{~nm}$ ${ }^{4} \mathrm{G}_{5 / 2} \rightarrow{ }^{6} \mathrm{H}_{5 / 2}$ shows the lowest intensity between the other two transitions. The glass containing $\mathrm{Sm}_{2} \mathrm{O}_{3}$ emits bright reddish-orange emission due to the obvious emissions at 562 $\left({ }^{4} \mathrm{G}_{5 / 2} \rightarrow{ }^{6} \mathrm{H}_{5 / 2}\right), 600\left({ }^{4} \mathrm{G}_{5 / 2} \rightarrow{ }^{6} \mathrm{H}_{7 / 2}\right)$, and $647\left({ }^{4} \mathrm{G}_{5 / 2} \rightarrow{ }^{6} \mathrm{H}_{9 / 2}\right) \mathrm{nm}$. As is evident in Figure. 7 the peak intensities enhanced with the increase of $\mathrm{Sm}_{2} \mathrm{O}_{3}$ concentration from 100 to $400 \mathrm{ppm}$ then the peak intensities decrease at $\mathrm{Sm}_{2} \mathrm{O}_{3}=500 \mathrm{ppm}$. This observable fact is called luminescence quenching. With increasing concentration of $\mathrm{Sm}_{2} \mathrm{O}_{3}$ the glass matrix becomes crowded by $\mathrm{Sm}^{3+}$ ions this reduces the Internuclear distance $\left(\mathrm{r}_{\mathrm{i}}\right)$ between $\mathrm{Sm}^{3+}-\mathrm{Sm}^{3+}$ ions also the distance between donor and acceptor centers decreases significantly ${ }^{[5]}$. Consequently, the excitation energy could be transferred from $\mathrm{Sm}^{3+}$ ion to another ion by the interaction between two active ions so the intensity of luminescence decreases ${ }^{[9,31]}$. The luminescence intensity of the emission spectral measurements of the prepared glasses has been obtained using $1931 \mathrm{CIE}$ chromaticity diagram. The CIE chromaticity coordinates are found in the range whitereddish- orange range, it is dependent on the concentration of Sm3+ ions in the host glass matrix (see Fig. 8).

FTIR spectroscopy is a precious technique to study different functional groups in the glass network structure. FTIR absorption spectra of the prepared glass samples were recorded in the wavenumber range from $400 \mathrm{~cm}^{-1}$ to $3600 \mathrm{~cm}^{-1}$ at ambient conditions and depicted in Figure.3.a. Deconvolution was applied on FTIR spectra, fourteen characteristic bands were indicated. These bands belonged to functional groups presented in the glass system as illustrated in Fig. (3.b). Table 3 includes the peak positions and their assignments. The peak in the wavenumber range of $415-422 \mathrm{~cm}^{-1}$ is ascribed to $\mathrm{Li}_{2} \mathrm{O}^{[13,16]}$. The peak of $432-444 \mathrm{~cm}^{-}$ ${ }^{1}$ is due to $(\mathrm{Na}-\mathrm{O})^{[17]}$. The peak around $460-480 \mathrm{~cm}^{-1}$ is ascribed to $\mathrm{Si}-\mathrm{O}-\mathrm{Si}$ bending vibration [18- 19-20]. The peak around 540-570 is attributed to the stretching vibration of $\mathrm{Sm}_{2} \mathrm{O}_{3}{ }^{[21]}$. The 
peak in the wavenumber range of $650-663 \mathrm{~cm}^{-1}$ is attributed to asymmetrical bending vibrations (v4) of Si-O-Si ${ }^{[12]}$. The peak in the range of 704- $712 \mathrm{~cm}^{-1}$ is due to the bending vibration of $\left[\mathrm{BO}_{3}\right]$ units ${ }^{[12,17-19,22]}$. The peak in the wavenumber range of $850-870 \mathrm{~cm}^{-1}$ is due to stretching vibrations of tri-, tetra-, and penta borate groups ${ }^{[20]}$. The peak which is lied between $931-955 \mathrm{~cm}^{-1}$ is attributed to $\mathrm{B}-\mathrm{O}$ stretch in $\mathrm{BO}_{4}$ units from di-borate groups ${ }^{[12]}$. The peak which is between $1033-1045 \mathrm{~cm}^{-1}$ is due to $\mathrm{Sm}^{3+}$ stretching vibration ${ }^{[23]}$ The peak which is between $1070-1115 \mathrm{~cm}^{-1}$ is due to the symmetric stretching vibration of $\mathrm{Si}-\mathrm{O}-\mathrm{Si}$ bonds ${ }^{[12]}$. The peak in the range of $1330-1345 \mathrm{~cm}^{-1}$ is attributed to $\mathrm{B}-\mathrm{O}$ stretch in $\mathrm{BO}_{3}$ units from varied types of borate groups ${ }^{[12]}$. The peak in the range of $1414-1426 \mathrm{~cm}^{-1}$ is attributed to $\mathrm{B}-\mathrm{O}$ stretching vibration of $\mathrm{BO}_{3}$ units in metaborate, pyroborate\& orthoborate groups ${ }^{[12]}$. The peak in the range of $1535-1549 \mathrm{~cm}^{-1}$ is due to stretching modes of Si-OH and $\mathrm{B}-\mathrm{O}$ stretch in $\mathrm{BO}_{4}$ units from tetrahedral groups ${ }^{[24]}$. The peak in the range of $1650-1660 \mathrm{~cm}^{-1}$ is due to the $\mathrm{BO}^{-}$bond in the isolated pyroborate group ${ }^{[12]}$. The peak of $\mathrm{Al}^{+}$wasn't indicated in IR absorbance spectra as shown in Fig.1, because the concentration of $\mathrm{Al}^{3+}$ was scanty and its signal of vibration frequency was very weak ${ }^{[18]}$. The groups like di, tri, Penta, meta, and boroxol rings with bridging or non-bridging oxygen ions participate in the formation of multicomponent borosilicate glasses ${ }^{[25]}$. In the glass network, the area below the curve of $\mathrm{BO}_{4}$ and $\mathrm{BO}_{3}$ was calculated. It was observed that the $\mathrm{BO}_{4}$ ratio in glass samples equal 0.3121, 0.3770, 0.387254, 0.4289, 0.43720, and 0.464381, respectively, when the concentration of $\mathrm{Sm}_{2} \mathrm{O}_{3}$ increases from 0.00 to $500 \mathrm{ppm}$. The presence of bridging oxygen was detected by four coordinated $\mathrm{BO}_{4}$ boron atoms which are a result of the conversion of three coordinated $\mathrm{BO}_{3}$ units ${ }^{[25]}$, also the peak lies in $1426 \mathrm{~cm}^{-1}$ shifted to $1414 \mathrm{~cm}^{-1}$. This shifting to lower wavenumber clarifies that the phonon energy of the glass system decreased because it depends on $\mathrm{BO}_{3}$ units ${ }^{[26]}$ which enhanced the efficiency of fluorescence ${ }^{[26]}$.

\section{CONCLUSION}

From the results which were obtained in the present studies, it can be concluded that; The glass samples of composition $\left(50 \mathrm{~B}_{2} \mathrm{O}_{3}-14 \mathrm{SiO}_{2}-20 \mathrm{Li}_{2} \mathrm{O}-15 \mathrm{Na}_{2} \mathrm{O}-\mathrm{Al}_{2} \mathrm{O}_{3}-\mathrm{xSm}_{2} \mathrm{O}_{3}\right)$, where $\mathrm{x}=0.0,100,200,300,400$, and $500 \mathrm{ppm}$ have been synthesized by the conventional melting and quenching method. The Color of all glass samples prepared was yellowish and transparent. The XRD patterns confirmed the amorphous nature of all glass samples. The density of the prepared glass samples was found to be increased with the increasing content of samarium. Furthermore, the molar volume of these glasses decreased which led to compaction of the BSLNA glass network. The FTIR analysis consisted of several bands which indicated 
the characteristic of Si-O and B-O vibrational groups. The optical absorption spectra of these glasses revealed that the fundamental absorption edge shifted to a longer wavelength as the content of $\mathrm{Sm}_{2} \mathrm{O}_{3}$ increased. The bandgap decreased by increasing $\mathrm{Sm}_{2} \mathrm{O}_{3}$ content. The refractive index and Urbach energy were found to increase with the increasing content of samarium. It was observed a strong orange-red emission owing to the transition ${ }^{4} \mathrm{G}_{5 / 2} /{ }^{6} \mathrm{H}_{7 / 2}$ for BSLNA doped glasses. The PL intensity for this transition was observed to be the maximum for BSLNA4 doped glass sample, then it reduced for glass with BSLNA5 doped glass, due to the luminescence quenching process. Also, CIE color co-ordinates have obtain that in the white- reddish- orange region, the emission of $\mathrm{Sm} 3+$ ions incorporated in the host glasses has appeared.

\section{Acknowledgment:}

The authors extend their appreciation to the Deanship of Scientific Research at King Khalid University (KKU) for funding this research project Number (R.G. P2/63/40).

\section{Reference}

1-N. Bouras, M.A.Madjoubi, M. Kolli, S.Benterki, M. Hamidouche, Thermal and mechanical characterization of borosilicate glass, Physics Procedia 2 (2009) 1135-114.

2- N. Elkhoshkhany, Eslam Syalam, El Sayed Yousef,' Kinetics characterization and visible photoluminescence spectroscopy of an erbium-doped tellurite glass' Results in Physics 14 (2019) 102370.

3- N. Elkhoshkhany, Hager M. Mohamed, El Sayed Yousef ' UV-Vis-NIR spectroscopy, structural and thermal properties of novel oxyhalide tellurite glasses with composition $\mathrm{TeO}_{2}$ $\mathrm{B}_{2} \mathrm{O}_{3}-\mathrm{SrCl}_{2}-\mathrm{LiF}-\mathrm{Bi}_{2} \mathrm{O}_{3}$ for optical application'’ Results in Physics 13 (2019) 102222.

4- I. Fuks-Janczarek, R. Miedzinski, M. Reben, El Sayed Yousef "' Linear and non-linear optical study of fluorotellurite glasses as a function of selected alkaline earth metals doped with $\mathrm{Er}^{3+}$, Optics \&Laser Tech. 111 (2019) 184.

5-A.A. El-Maaref, E. A. Wahab, Kh S. Shaaban, M. Abdelawwad, M. S. Koubisy, J. Boercsoek, El Sayed Yousef, Visible and mid-infrared spectral emissions and radiative rates calculations of $\mathrm{Tm}^{3+}$ doped BBLC glass, Spectrochimica Acta Part A- Molecular and Biomolecular Spectroscopy, 242, (2020) 118774.

6-Kh S. Shaaban, E. A. Wahab, A.A. El-Maaref, M. Abdelawwad, El Sayed Yousef, H. Wilke, H. Hillmer, J. Borcsok, Judd-Ofelt analysis and physical properties of erbium modified cadmium lithium gadolinium silicate glasses' J. of Mat. Sci. Mat. In Elect. 31 ( 2020) 4986.

7- K. Peacock, K. S. Long, Astronomical Telescope: A New Generation, APL Technical 
Digest, Volume 10, Number 1 (1989).

8- M. I. Ojovan and W.E. Lee. An Introduction to Nuclear Waste Immobilization, Elsevier, Amsterdam, 315 p. (2005).

9- P. Beeker, Borate Materials in Nonlinear Optics, Adv. Mater. 10 (1998) 979.

10- R. A. Talewar, Sk. Mahamuda, K. Swapna, M. Venkateswarlu, A.S. Rao, Spectroscopic studies of Sm3+ ions doped alkaline-earth chloroborate glasses for visible photonic applications, Materials Characterization 144 (2018) 274-286.

11- Peuchert, U., Kunert, C., Bartsch, R., 2004. Borosilicate glass with high chemical resistance and use thereof. US Patent: 6,794,323.)

12-Marques, P., 2008. Borosilicate glass compositions and uses thereof. US Patent: $7,341,966$.

13- Kokubu, Y., Chiba, J., Saita, K., 1987. Porous glass, the process for its production, and glass material used for the production. US Patent: 4,665,039.

14- S. Mohan, S. Kaur, D. P. Singh, P. Kaur, Structural and luminescence properties of samarium doped lead aluminum borate glasses, Optical Materials 73 (2017) 223-233.

15- I. I. Kindrat, B. V. Padlyak, A. Drzewiecki, Luminescence properties of the Sm-doped borate glasses, Journal of Luminescence 166 (2015) 264-275.

16- S. Thomas, Sk. N. Rasool, M. Rathaiah, V. Venkatramu, C. Joseph, N. V. Unnikrishnan, Spectroscopic and dielectric studies of Sm3+ ions in lithium zinc borate glasses, Journal of Non-Crystalline Solids 376 (2013) 106-116.

17- P. Goyal, K. S. Yogesh, S. Pal, U. C. Bind, S. C. Huang, S. L. Chung, Structural, optical and physical analysis of $\mathrm{B}_{2} \mathrm{O}_{3}-\mathrm{SiO}_{2}-\mathrm{Na}_{2} \mathrm{O}-\mathrm{PbO}-\mathrm{ZnO}$ glass with $\mathrm{Sm}^{3+}$ ions for reddishorange laser emission, Journal of Luminescence 192 (2017) 1227-1234.

18- N. Elkhoshkhany, S. Y. Marzouk, M. A. Khattab, S. A. Dessouki, Influence of Sm2O3 addition on Judd-Ofelt parameters, thermal and optical properties of the TeO2-Li2O-ZnONb2O5 glass system, Materials Characterization 144 (2018) 274-286.

19- S. Y. El-Zaiat, M. B. El-Den, S. U. El-Kameesy, Y. A. El-Gammam, Spectral dispersion of linear optical properties for $\mathrm{Sm} 2 \mathrm{O} 3$ doped B2O3-PbO-A12O3 glasses, Optics \& Laser Technology 44 (2012) 1270-1276.

20- Inamullah Khan, G. Rooh, S. Mukamil, J. Kaewkhao, L. Shamshad, N. Sangwaranatee, Investigation of the luminescence properties of $\mathrm{Sm} 3+$ activated mixed alkali borate glasses, Materials Today: Proceedings 5 (2018) 15019-15023.

21- J. Pisarska, A. Kos, M. Sołtys, A. Górny, E. Pietrasik, W. A. Pisarski, Spectroscopy and energy transfer in $\mathrm{Tb} 3+/ \mathrm{Sm} 3+$ co-doped lead borate glasses, Journal of Luminescence 195 (2018) 87-95.

22- El S. Yousef, M. M. Elokr, Y. M. AbouDeif, Optical, elastic properties and DTA of TNZP host tellurite glasses doped with Er3+ ions, Journal of Molecular Structure 1108 (2016) 257-262. 
23- N. Elkhoshkhany, S. Y. Marzouk, S. Shahin, Synthesis and optical properties of new fluoro-tellurite glass within (TeO2-ZnO-LiF-Nb2O5-NaF) system, Journal of Non-Crystalline Solids (2017), http://dx.doi.org/10.1016/j.jnoncrysol.2017.07.012.

24- Sk. N. Rasool, L. R. Moorthy, C. K. Jayasankar, Spectroscopic Investigation of Sm3+ doped phosphate based glasses for reddish-orange emission, Optics Communications 311 (2013) 156-162.

25- D. D. Ramteke, V. Y. Ganvir, S. R. Munishwar, R. S. Gedam, Concentration Effect of Sm3+ Ions on Structural and Luminescence Properties of Lithium Borate Glasses, Physics Procedia 76 ( 2015) $25-30$.

26- S. S. Hajer, M. K. Halimah, Z. Azmi, M. N. Azlan, Optical Properties of ZincBorotellurite Doped Samarium, Chalcogenide Letters, 11, No. 11 (2014) 553-566.

27- F. Ahmadi, R. Hussin, S. K. Ghoshal, Structural and physical properties of Sm3+ doped magnesium zinc sulfophosphate glass, Bull. Mater. Sci., 40, No. 6 (2017) 1097-1104.

28- N. Luewarasirikul, J. Kaewkhao, Spectroscopic properties and Judd-Ofelt analysis of Sm3+ ions in barium sodium borate glasses, Materials Today: Proceedings 4 (2017) 62246233.

29- K. V. Raju, S. Sailaja, M. B. Reddy, P. Giridhar, C. N. Raju, B. S. Reddy, Effect of Concentration on the Photoluminescence Properties of $\mathrm{Sm}^{3+}$ and $\mathrm{Dy}^{3+}$ : Cadmium Lithium Boro Tellurite Glasses, Journal of Nanoscience and Nanotechnology, 12 (2012) 1662-1666. 


\section{Figure Captions:}

Figure 1: X-Ray diffraction patterns of the prepared samples.

Figure 2: Optical absorption spectra for prepared glass samples doped with $\mathrm{Sm}_{2} \mathrm{O}_{3}$ in the range from $400-1800 \mathrm{~nm}$.

Figure 3: $(\alpha h v)^{1 / 2}$ in $\mathrm{cm}^{-1 / 2} \mathrm{eV}^{1 / 2}$ vs $h v \mathrm{eV}$ of prepared glass

Figure 4: Variation of $\ln (\alpha)$ against hv for all prepared glass samples.

Figure 5: The absorption and emission cross-sections for the prepared glass samples doped with $\mathrm{Sm}_{2} \mathrm{O}_{3}$, [A] $\mathrm{Sm}^{3+}$ 100ppm, [B] Sm${ }^{3+}$ 200ppm, [C] $\mathrm{Sm}^{3+} 300 \mathrm{ppm}$, [D] $\mathrm{Sm}^{3+}$ 400ppm, [E] Sm ${ }^{3+}$ 500ppm.

Figure 6: Gain coefficient for the prepared glass samples doped with $\mathrm{Sm}_{2} \mathrm{O}_{3}$. [A] $\mathrm{Sm}^{3+} 100$ ppm, [B] Sm ${ }^{3+}$ 200ppm, [C] Sm ${ }^{3+} 300 \mathrm{ppm}$, [D] Sm${ }^{3+} 400 \mathrm{ppm}$, [E] Sm $\mathrm{Sm}^{3+} 500 \mathrm{ppm}$.

Figure 7: Emission spectra for the prepared glass samples doped with $\mathrm{Sm}_{2} \mathrm{O}_{3}$ under excitation wavelength $(402 \mathrm{~nm})$.

Figure 8: CIE-1931 chromaticity diagram for prepared glass BSLNA under excitation wavelength (402nm)

Figure 9: Deconvolution of FTIR spectra for BSLNA2 glass sample.

$$
\mathrm{Sm}^{3+} 200 \mathrm{ppm}
$$


Table (1): Compositions (mol\%) and shapes of our prepared glasses system $\left(50 \mathrm{~B}_{2} \mathrm{O}_{3}-\right.$ $\left.14 \mathrm{SiO}_{2}-20 \mathrm{Li}_{2} \mathrm{O}-15 \mathrm{Na}_{2} \mathrm{O}-1 \mathrm{Al}_{2} \mathrm{O}_{3}-\mathrm{X} \mathrm{Sm}_{2} \mathrm{O}_{3}\right)$.

\begin{tabular}{|c|c|c|}
\hline Glass code & Chemical composition & $\begin{array}{l}\text { Samples } \\
\text { shape }\end{array}$ \\
\hline BSLNA0 & $50 \mathrm{~B}_{2} \mathrm{O}_{3}-14 \mathrm{SiO}_{2}-20 \mathrm{Li}_{2} \mathrm{O}-15 \mathrm{Na}_{2} \mathrm{O}-1 \mathrm{Al}_{2} \mathrm{O}_{3}-0 \mathrm{Sm}_{2} \mathrm{O}_{3}$ & \\
\hline BSLNA1 & $50 \mathrm{~B}_{2} \mathrm{O}_{3}-14 \mathrm{SiO}_{2}-20 \mathrm{Li}_{2} \mathrm{O}-15 \mathrm{Na}_{2} \mathrm{O}-1 \mathrm{Al}_{2} \mathrm{O}_{3}-100 p p m \mathrm{Sm}_{2} \mathrm{O}_{3}$ & \\
\hline BSLNA2 & $50 \mathrm{~B}_{2} \mathrm{O}_{3}-14 \mathrm{SiO}_{2}-20 \mathrm{Li}_{2} \mathrm{O}-15 \mathrm{Na}_{2} \mathrm{O}-1 \mathrm{Al}_{2} \mathrm{O}_{3}-200 \mathrm{ppm} \mathrm{Sm}_{2} \mathrm{O}_{3}$ & \\
\hline BSLNA3 & $50 \mathrm{~B}_{2} \mathrm{O}_{3}-14 \mathrm{SiO}_{2}-20 \mathrm{Li}_{2} \mathrm{O}-15 \mathrm{Na}_{2} \mathrm{O}-1 \mathrm{Al}_{2} \mathrm{O}_{3}-300 \mathrm{ppm} \mathrm{Sm}_{2} \mathrm{O}_{3}$ & \\
\hline BSLNA4 & $50 \mathrm{~B}_{2} \mathrm{O}_{3}-14 \mathrm{SiO}_{2}-20 \mathrm{Li}_{2} \mathrm{O}-15 \mathrm{Na}_{2} \mathrm{O}-1 \mathrm{Al}_{2} \mathrm{O}_{3}-400 \mathrm{ppm} \mathrm{Sm}_{2} \mathrm{O}_{3}$ & \\
\hline BSLNA5 & $50 \mathrm{~B}_{2} \mathrm{O}_{3}-14 \mathrm{SiO}_{2}-20 \mathrm{Li}_{2} \mathrm{O}-15 \mathrm{Na}_{2} \mathrm{O}-1 \mathrm{Al}_{2} \mathrm{O}_{3}-500 \mathrm{ppm} \mathrm{Sm}_{2} \mathrm{O}_{3}$ & \\
\hline
\end{tabular}


Table (2): The values of the density $\left(\mathrm{g} / \mathrm{cm}^{3}\right)$, molar volume $\left(\mathrm{cm}^{3} / \mathrm{mol}\right)$, and oxygen packing density (g.atom/L) of the prepared glass samples.

\begin{tabular}{|c|c|c|c|c|}
\hline Glasses code & Density $\left(\mathrm{g} / \mathrm{cm}^{3}\right)$ & $\begin{array}{c}\text { Molar Volume } \\
\left(\mathrm{cm}^{3} / \mathrm{mol}\right)\end{array}$ & $\begin{array}{c}\text { Oxygen } \\
\text { packing } \\
\text { density } \\
(\mathrm{mol} / \mathrm{l})\end{array}$ & $\begin{array}{c}\text { Average boron- } \\
\text { boron separation } \\
\left\langle\mathrm{d}^{\mathrm{B}-\mathrm{B}}>(\mathrm{nm})\right.\end{array}$ \\
\hline BSLNA0 & 2.397 & 27.58 & 78.31 & 0.5728 \\
\hline BSLNA1 & 2.423 & 27.29 & 79.14 & 0.565 \\
\hline BSLNA2 & 2.5158 & 26.31 & 82.133 & 0.5528 \\
\hline BSLNA3 & 2.5632 & 25.83 & 83.65 & 0.5445 \\
\hline BSLNA4 & 2.5961 & 25.52 & 84.69 & 0.5375 \\
\hline BSLNA5 & 2.62566 & 25.25 & 85.62 & 0.522 \\
\hline
\end{tabular}


Table (3): Indirect optical band gap energy $E_{o p t}^{\text {in }}$, Urbach energy $\Delta \mathrm{E}$ and refractive index, $\mathrm{n}$.

\begin{tabular}{|l|c|c|c|c|c|c|c|}
\hline $\begin{array}{c}\text { Glasses } \\
\text { code }\end{array}$ & $\begin{array}{c}\text { Refractive } \\
\text { index (n) }\end{array}$ & $\begin{array}{c}\text { Indirect } \\
\text { bandgap } \\
\mathrm{E}_{\mathrm{opt}}(\mathrm{eV})\end{array}$ & $\begin{array}{c}\text { Urbach } \\
\text { energy } \\
\Delta \mathrm{E}(\mathrm{eV})\end{array}$ & $\begin{array}{c}\text { Molar } \\
\text { refraction } \\
\left(\mathrm{R}_{\mathrm{m}}, \mathrm{cm}^{3}\right. \\
\mathrm{mol}^{-1}\end{array}$ & $\begin{array}{c}\text { Polarizability }\left(\alpha_{\mathrm{m}}\right) \\
\left(\times 10^{-24}\right)\left(\mathrm{cm}^{3}\right)\end{array}$ & $\begin{array}{c}\text { Dielectric } \\
\text { constant } \\
(\varepsilon)\end{array}$ & $\begin{array}{c}\text { Refraction } \\
\text { loss }\left(\mathrm{R}_{\mathrm{L}}\right)\end{array}$ \\
\hline BSLNA0 & 2.2497 & 3.61 & 0.36 & 15.86 & 6.29 & 5.061 & 0.14 \\
\hline BSLNA1 & 2.2628 & 3.55 & 0.45 & .158 & 6.27 & 5.12 & 0.149 \\
\hline BSLNA2 & 2.294 & 3.41 & 0.49 & 15.44 & 6.12 & 5.26 & 0.154 \\
\hline BSLNA3 & 2.32066 & 3.3 & 0.51 & 15.48 & 6.14 & 5.32 & 0.158 \\
\hline BSLNA4 & 2.3452 & 3.2 & 0.55 & 15.31 & 6.072 & 5.5 & 0.1617 \\
\hline BSLNA5 & 2.736 & 2.0 & 1.37 & 17.26 & 6.85 & 7.49 & 0.215 \\
\hline
\end{tabular}


Table (4): Physical properties of prepared glass samples.

\begin{tabular}{|l|c|c|c|c|}
\hline $\begin{array}{c}\text { Sample } \\
\text { glass }\end{array}$ & $\begin{array}{c}\text { Polaron radius } \\
\text { of } \mathrm{Sm}^{3+} \text { ions } \\
(\mathrm{A})( \pm 1.5039)\end{array}$ & $\begin{array}{c}\text { The internuclear } \\
\text { distance of } \mathrm{Sm}^{3+} \\
\text { ions }(\mathrm{A})( \pm 0.3732)\end{array}$ & $\begin{array}{c}\text { The field } \\
\text { strength of } \mathrm{Sm}^{3+} \\
\text { ions }(\times 1014 \\
\left.\mathrm{cm}^{-2}\right)( \pm 1.4875)\end{array}$ & $\begin{array}{c}\mathrm{Sm}^{3+} \text { ions } \\
\text { concentration } \\
\left(\times 1020 \text { ion }^{-3}\right) \\
( \pm 0.5990)\end{array}$ \\
\hline BSLNA0 & 0 & 0 & 0 & 0 \\
\hline BSLNA1 & 6.669 & 16.550 & 3.8807 & 2.20591 \\
\hline BSLNA2 & 5.2279 & 12.974 & 5.5014 & 4.5783 \\
\hline BSLNA3 & 4.539 & 11.2662 & 7.298 & 6.993 \\
\hline BSLNA4 & 4.1075 & 10.1943 & 8.912 & 9.439 \\
\hline BSLNA5 & 3.79954 & 9.429 & 10.415 & 11.926 \\
\hline
\end{tabular}


Table (5): Experimental ( $\left.f_{\text {exp }}\right)$ and calculated $\left(f_{\text {cal }}\right)$ oscillator strengths along (from the ground state, ${ }^{6} \mathrm{H}_{5 / 2}$ ), with JO parameters of prepared glass samples.

\begin{tabular}{|c|c|c|c|c|c|c|c|c|c|c|c|c|}
\hline \multirow{2}{*}{$\begin{array}{c}\text { Transition } \\
{ }^{6} \mathrm{H}_{5 / 2} \rightarrow\end{array}$} & \multirow{2}{*}{$\begin{array}{l}\text { Wavelength } \\
\text { (nm) }\end{array}$} & \multirow{2}{*}{$\begin{array}{l}\text { Energy } \\
\left(\mathrm{cm}^{-1}\right)\end{array}$} & \multicolumn{2}{|c|}{ BSLNA1 } & \multicolumn{2}{|c|}{ BSLNA2 } & \multicolumn{2}{|c|}{ BSLNA3 } & \multicolumn{2}{|c|}{ BSLNA4 } & \multicolumn{2}{|c|}{ BSLNA5 } \\
\hline & & & $f_{\text {exp }}$ & $f_{\text {cal }}$ & $f_{\text {exp }}$ & $f_{\text {cal }}$ & $f_{\text {exp }}$ & $f_{\text {cal }}$ & $f_{e x p}$ & $f_{\text {cal }}$ & $f_{\text {exp }}$ & $f_{c a l}$ \\
\hline${ }^{6} \mathrm{~F}_{1 / 2}$ & 1563 & 6397 & 0.3534 & 0.7149 & 0.2598 & 0.5064 & 0.2296 & 0.4403 & 0.1324 & 0.3628 & 0.1798 & 0.4076 \\
\hline${ }^{6} \mathrm{H}_{15 / 2}$ & 1536 & 6510 & 0.4514 & 0.0134 & 0.3398 & 0.0095 & 0.3045 & 0.0083 & 0.3353 & 0.0101 & 0.4049 & 0.0085 \\
\hline${ }^{6} \mathrm{~F}_{3 / 2}$ & 1505 & 6644 & 1.8852 & 1.3659 & 1.346 & 0.9892 & 1.1732 & 0.8676 & 1.1448 & 0.8024 & 1.3018 & 0.9738 \\
\hline${ }^{6} \mathrm{~F}_{5 / 2}$ & 1402 & 7131 & 1.725 & 1.8584 & 1.2575 & 1.3615 & 1.1073 & 1.1995 & 1.0284 & 1.1705 & 1.3781 & 1.4657 \\
\hline${ }^{6} \mathrm{~F}_{7 / 2}$ & 1253 & 7980 & 1.9952 & 2.226 & 1.4642 & 1.6007 & 1.2936 & 1.4059 & 1.5394 & 1.5757 & 1.4118 & 1.5609 \\
\hline${ }^{6} \mathrm{~F}_{9 / 2}$ & 1094 & 9135 & 1.1945 & 1.1933 & 0.8676 & 0.8495 & 0.7709 & 0.7447 & 0.8304 & 0.8852 & 0.8443 & 0.7792 \\
\hline${ }^{6} \mathrm{~F}_{11 / 2}$ & 950 & 10517 & 0.2739 & 0.1648 & 0.1892 & 0.1169 & 0.1636 & 0.1025 & 0.1476 & 0.1238 & 0.2815 & 0.1053 \\
\hline${ }^{4} \mathbf{I}_{13 / 2}$ & 484 & 20661 & 3.056 & 0.096 & 1.6071 & 0.0681 & 1.1917 & 0.0596 & 1.1011 & 0.0724 & 1.0696 & 0.061 \\
\hline${ }^{4} \mathrm{~F}_{7 / 2}$ & 435 & 22988 & 2.3345 & 0.0006 & 0.8993 & 0.0004 & 0.7762 & 0.0004 & 0.4689 & 0.0005 & 0.6955 & 0.0004 \\
\hline $\begin{array}{c}\Omega_{2} \\
10^{-20} \mathrm{~cm}^{2}\end{array}$ & & & \multicolumn{2}{|c|}{3.6877} & \multicolumn{2}{|c|}{2.6119} & \multicolumn{2}{|c|}{2.2711} & \multicolumn{2}{|c|}{1.8716} & \multicolumn{2}{|c|}{2.1026} \\
\hline $\begin{array}{c}\Omega_{4} \\
10^{-20} \mathrm{~cm}^{2}\end{array}$ & & & \multicolumn{2}{|c|}{6.1114} & \multicolumn{2}{|c|}{4.488} & \multicolumn{2}{|c|}{3.9574} & \multicolumn{2}{|c|}{3.9021} & \multicolumn{2}{|c|}{4.9141} \\
\hline $\begin{array}{c}\Omega_{6} \\
10^{-20} \mathrm{~cm}^{2} \\
\end{array}$ & & & \multicolumn{2}{|c|}{3.1274} & \multicolumn{2}{|c|}{2.2181} & \multicolumn{2}{|c|}{1.943} & \multicolumn{2}{|c|}{2.3582} & \multicolumn{2}{|c|}{1.9861} \\
\hline RMS & & & \multicolumn{2}{|c|}{0.7540} & \multicolumn{2}{|c|}{0.7547} & \multicolumn{2}{|c|}{0.76163} & \multicolumn{2}{|c|}{0.7510} & \multicolumn{2}{|c|}{0.775} \\
\hline
\end{tabular}


Table (6): Calculated branching ratio $(\beta)$ and lifetime $(\tau, \mathrm{ms})$ of prepared glass samples.

\begin{tabular}{|c|c|c|c|c|c|c|c|c|c|c|}
\hline $\begin{array}{l}\text { Transition } \\
{ }^{6} \mathrm{H}_{5 / 2} \rightarrow\end{array}$ & \multicolumn{2}{|c|}{ BSLNA1 } & \multicolumn{2}{c|}{ BSLNA2 } & \multicolumn{2}{c|}{ BSLNA3 } & \multicolumn{2}{c|}{ BSLNA4 } & \multicolumn{2}{c|}{ BSLNA5 } \\
\hline & $B$ & $\tau(\mathrm{ms})$ & $\beta$ & $\tau(\mathrm{ms})$ & $\beta$ & $\tau(\mathrm{ms})$ & $\beta$ & $\tau(\mathrm{ms})$ & $\beta$ & $\tau(\mathrm{ms})$ \\
\hline${ }^{6} \mathrm{~F}_{1 / 2}$ & 0.5462 & 3.0156 & 0.5359 & 4.0249 & 0.5323 & 4.5533 & 0.4860 & 4.9740 & 0.4584 & 4.0774 \\
\hline${ }^{6} \mathrm{H}_{15 / 2}$ & 0.0523 & 115.68 & 0.0512 & 153.82 & 0.0509 & 173.085 & 0.0520 & 143.484 & 0.0490 & 156.947 \\
\hline${ }^{6} \mathrm{~F}_{3 / 2}$ & 0.5223 & 2.6317 & 0.5227 & 3.5044 & 0.5228 & 3.9581 & 0.5111 & 4.1247 & 0.5303 & 3.4445 \\
\hline${ }^{6} \mathrm{~F}_{5 / 2}$ & 0.4546 & 1.9485 & 0.4611 & 2.6003 & 0.4628 & 2.9338 & 0.4484 & 2.8721 & 0.5058 & 2.5279 \\
\hline${ }^{6} \mathrm{~F}_{7 / 2}$ & 0.3804 & 1.2087 & 0.3730 & 1.5899 & 0.3699 & 1.7766 & 0.4077 & 1.7233 & 0.3808 & 1.5869 \\
\hline${ }^{6} \mathrm{~F}_{9 / 2}$ & 0.2828 & 1.2172 & 0.2796 & 1.6296 & 0.2800 & 1.8346 & 0.3045 & 1.6545 & 0.2695 & 1.6210 \\
\hline${ }^{6} \mathrm{~F}_{11 / 2}$ & 0.0223 & 1.1857 & 0.0224 & 1.5905 & 0.0223 & 1.7906 & 0.0245 & 1.5736 & 0.0218 & 1.5776 \\
\hline
\end{tabular}


Table (7): Positions and assignments of FTIR bands of the $\left(\mathrm{B}_{2} \mathrm{O}_{3}-\mathrm{SiO}_{2}-\mathrm{Li}_{2} \mathrm{O}-\mathrm{Na}_{2} \mathrm{O}-\mathrm{Al}_{2} \mathrm{O}_{3}-\right.$ $\mathrm{Sm}_{2} \mathrm{O}_{3}$ ) glass system.

\begin{tabular}{|c|c|}
\hline Wavenumber $\left(\mathrm{cm}^{-1}\right)$ & Assignment \\
\hline (a) $415-425$ & Specific vibration of $\mathrm{Li}_{2} \mathrm{O}$ in the glass network \\
\hline (b) $432-444$ & Specific vibration of $\mathrm{Na}-\mathrm{O}$ in the glass network \\
\hline (c) $460-480$ & bending vibration of $\mathrm{Si}-\mathrm{O}-\mathrm{Si}$ \\
\hline (d) $540-570$ & Stretching vibration of $\mathrm{Sm}_{2} \mathrm{O}_{3}$ \\
\hline (e)650-663 & Asymmetrical bending vibrations (v4) of $\mathrm{Si}-\mathrm{O}-\mathrm{Si}$ \\
\hline (f) $704-712$ & Bending vibrations B-O-B \\
\hline (g) $850-870$ & Stretching vibrations of tri-, tetra/ penta borate groups \\
\hline (h)931-950 & $\mathrm{B}-\mathrm{O}$ stretch in $\mathrm{BO} 4$ units from di-borate groups \\
\hline (i) $1033-1045$ & $\mathrm{Sm}^{+3}$ stretching vibration \\
\hline (j)1070-1115 & Symmetric stretching vibration of $\mathrm{Si}-\mathrm{O}-\mathrm{Si}$ bonds \\
\hline (k)1330-1345 & $\mathrm{B}-\mathrm{O}$ stretch in $\mathrm{BO} 3$ units from varied types of borate groups \\
\hline (1)1414-1426 & $\begin{array}{l}\mathrm{B}-\mathrm{O} \text { Stretching vibration of } \mathrm{BO} 3 \text { units in metaborate, pyroborate } \\
\& \text { orthoborate groups }\end{array}$ \\
\hline (m) $1535-1549$ & $\begin{array}{l}\text { Stretching modes of } \mathrm{Si}-\mathrm{OH} \text { and } \mathrm{B}-\mathrm{O} \text { stretch in } \mathrm{BO} 4 \text { units from } \\
\text { tetrahedral groups }\end{array}$ \\
\hline (n) $1650-1660$ & $\mathrm{~B}-\mathrm{O}^{-}$bond in isolated pyroborate group \\
\hline
\end{tabular}




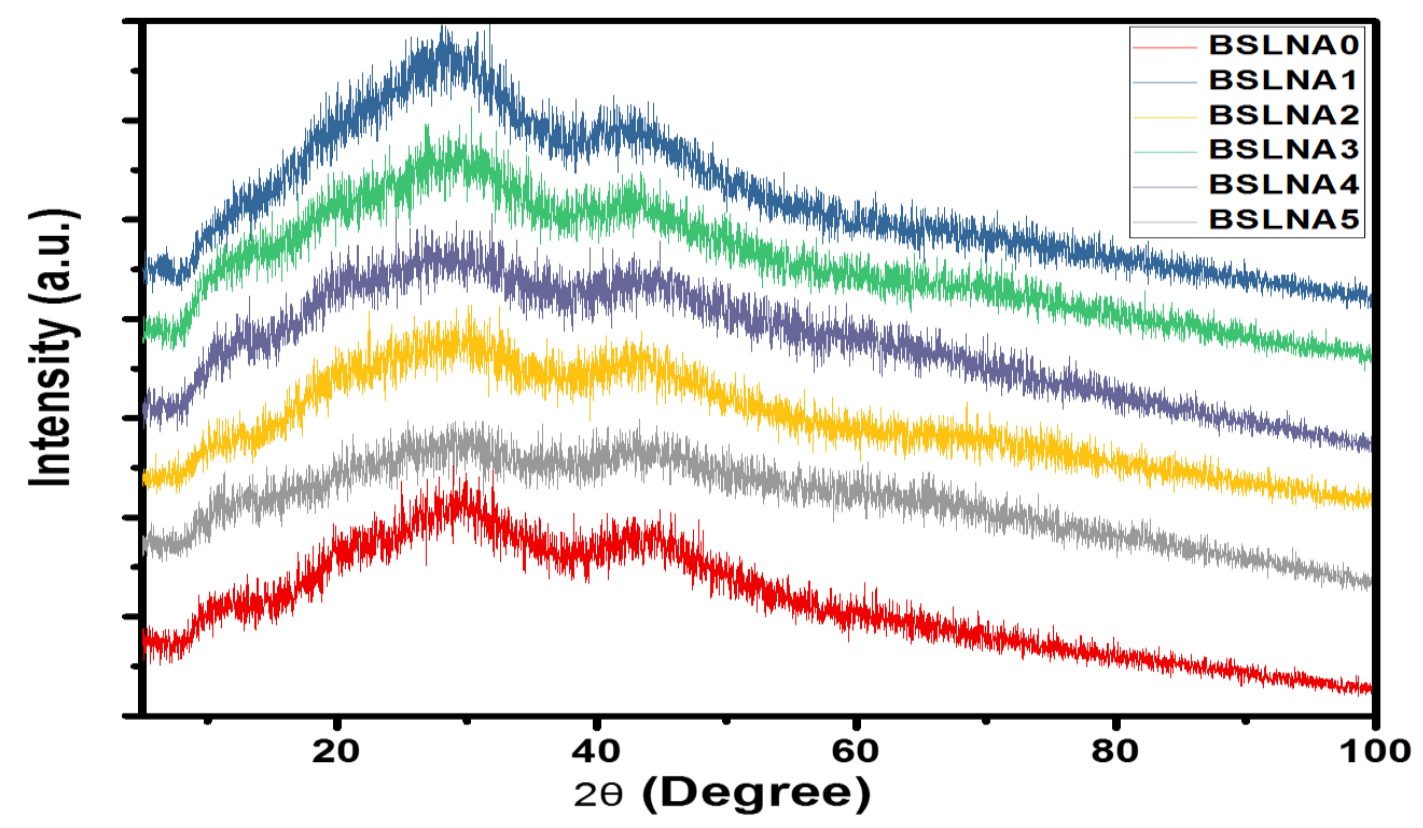

Figure 1: X-ray diffraction patterns of the prepared samples. 


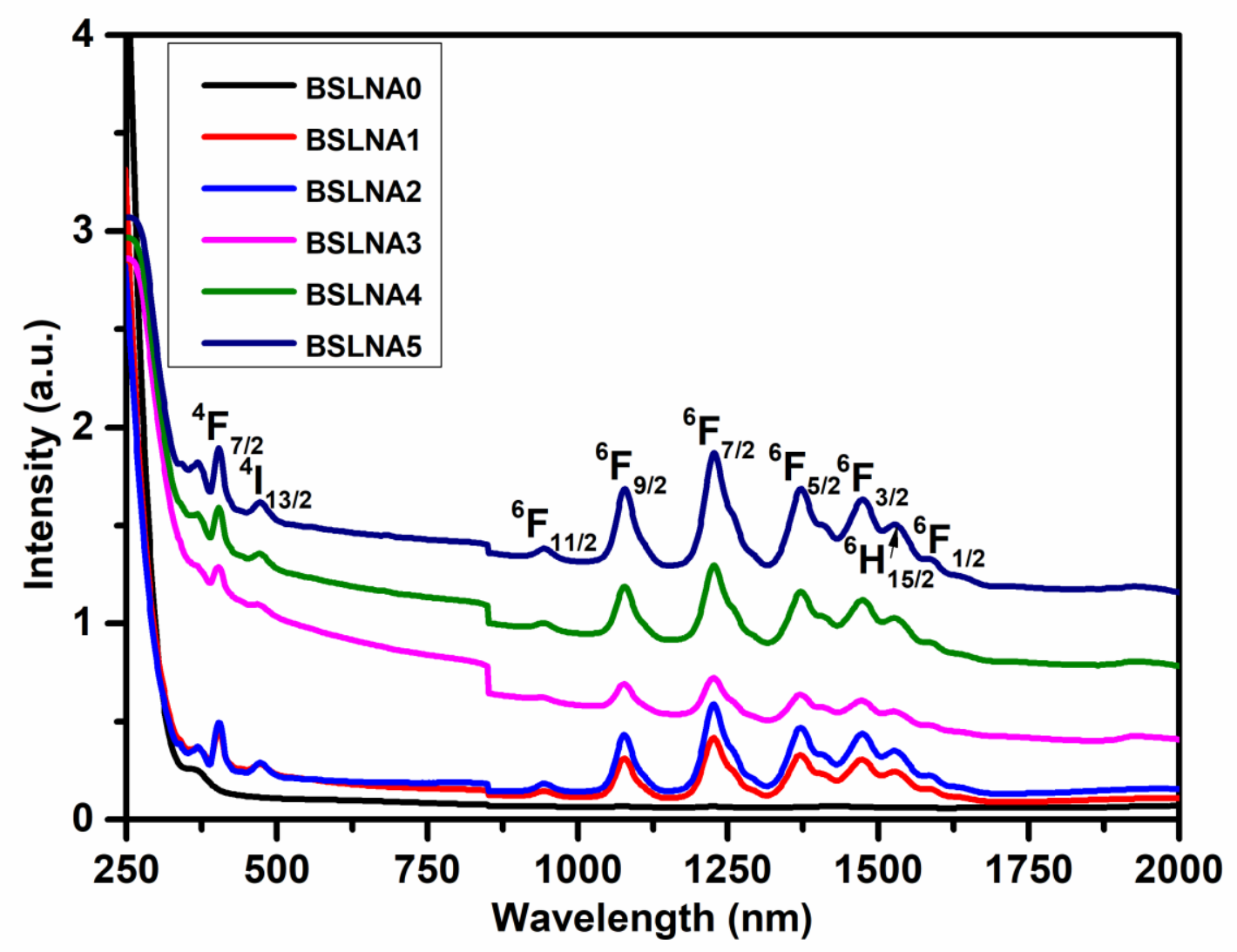

Figure 2: Optical absorption spectra for prepared glass doped with $\mathrm{Sm}_{2} \mathrm{O}_{3}$ in the range from 250- 2000nm. 


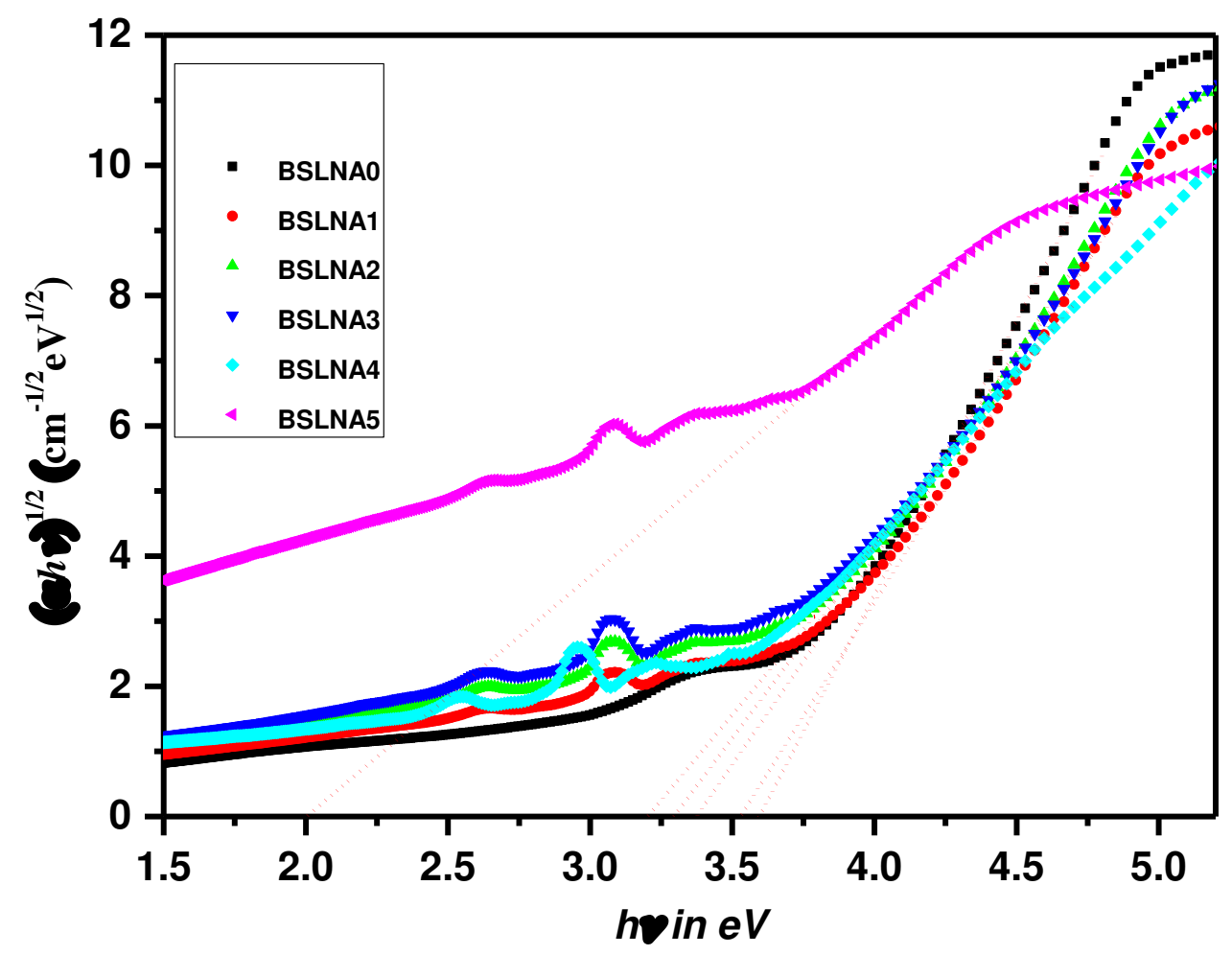

Figure 3: $(\alpha h v)^{1 / 2}$ in $\mathrm{cm}^{-1 / 2} \mathrm{eV}^{1 / 2} \mathrm{vs} h v \mathrm{eV}$ of prepared glass 


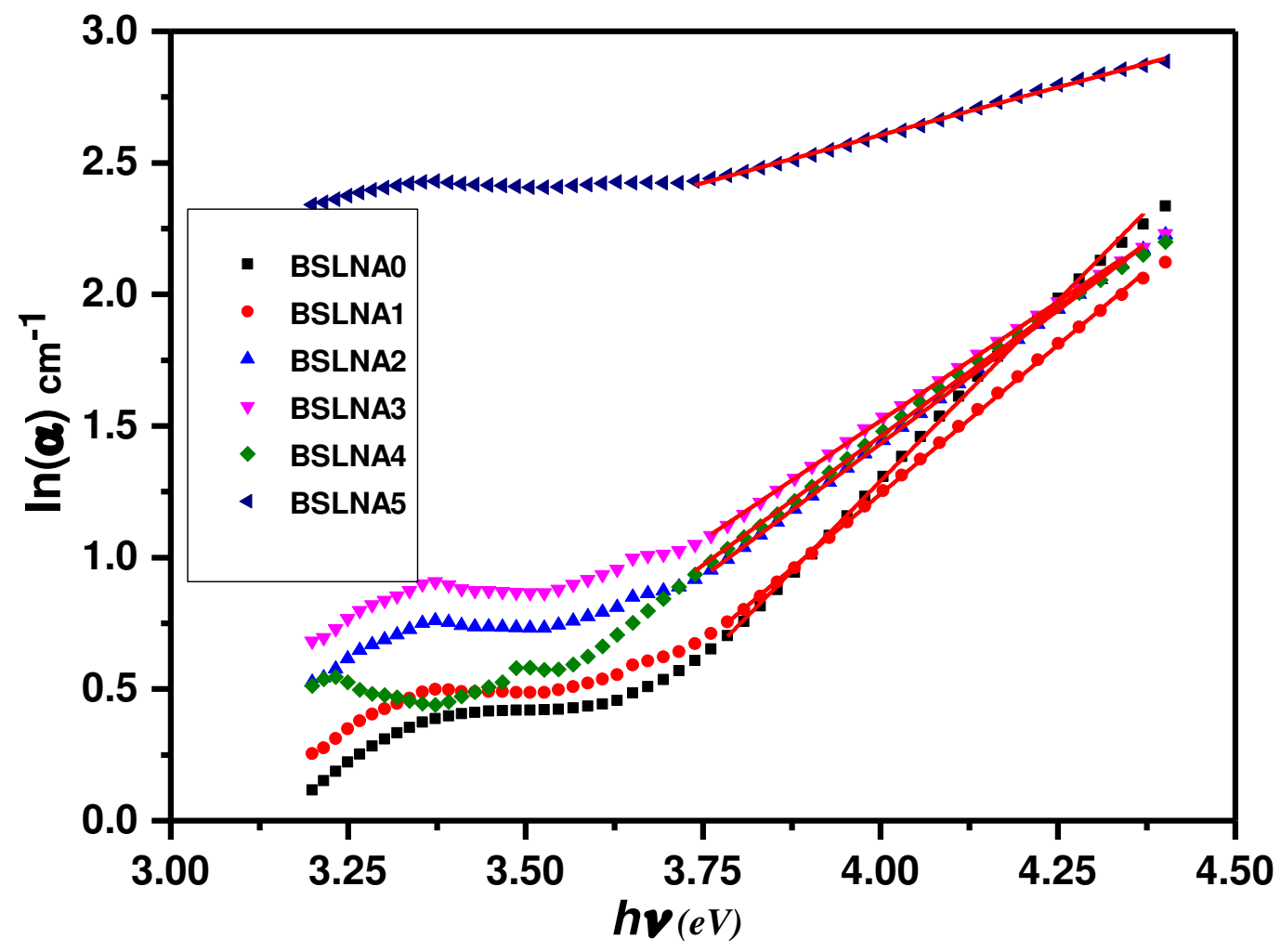

Figure 4: $\ln \alpha\left(\mathrm{cm}^{-1}\right)$ vs $h v \mathrm{eV}$ of prepared glass. 

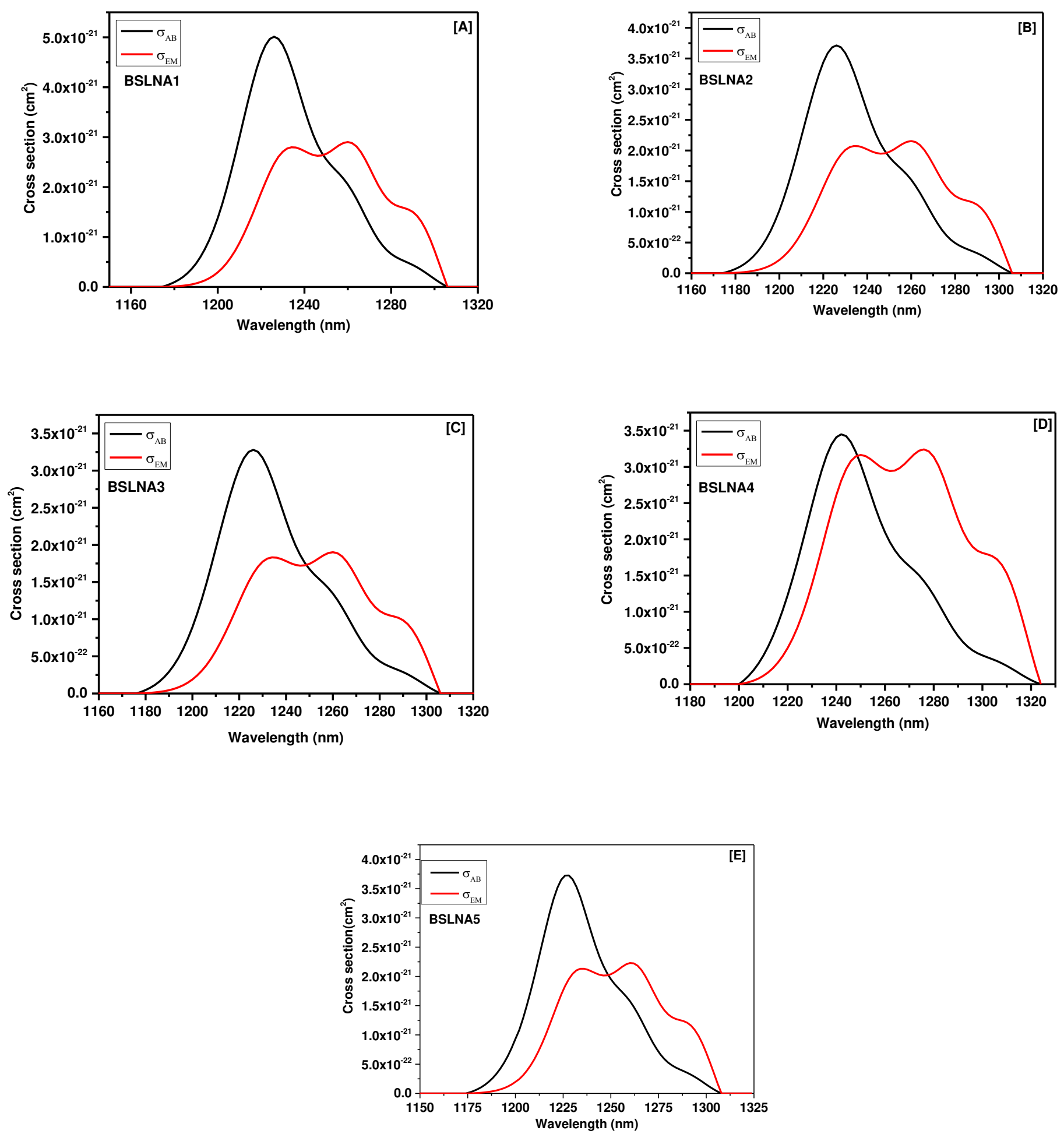

Figure 5: Absorption cross-sections $\sigma_{A B}(\lambda)$ and stimulated emission cross section $\sigma_{S E}(\lambda)$ of doped with $\mathrm{Sm}_{2} \mathrm{O}_{3}$. [A] $\mathrm{Sm}^{3+} 100 \mathrm{ppm},[\mathrm{B}] \mathrm{Sm}^{3+} 200 \mathrm{ppm},[\mathrm{C}] \mathrm{Sm}^{3+} 300 \mathrm{ppm}$, [D] $\mathrm{Sm}^{3+} 400 \mathrm{ppm},[\mathrm{E}] \mathrm{Sm}^{3+}$ 500ppm. 

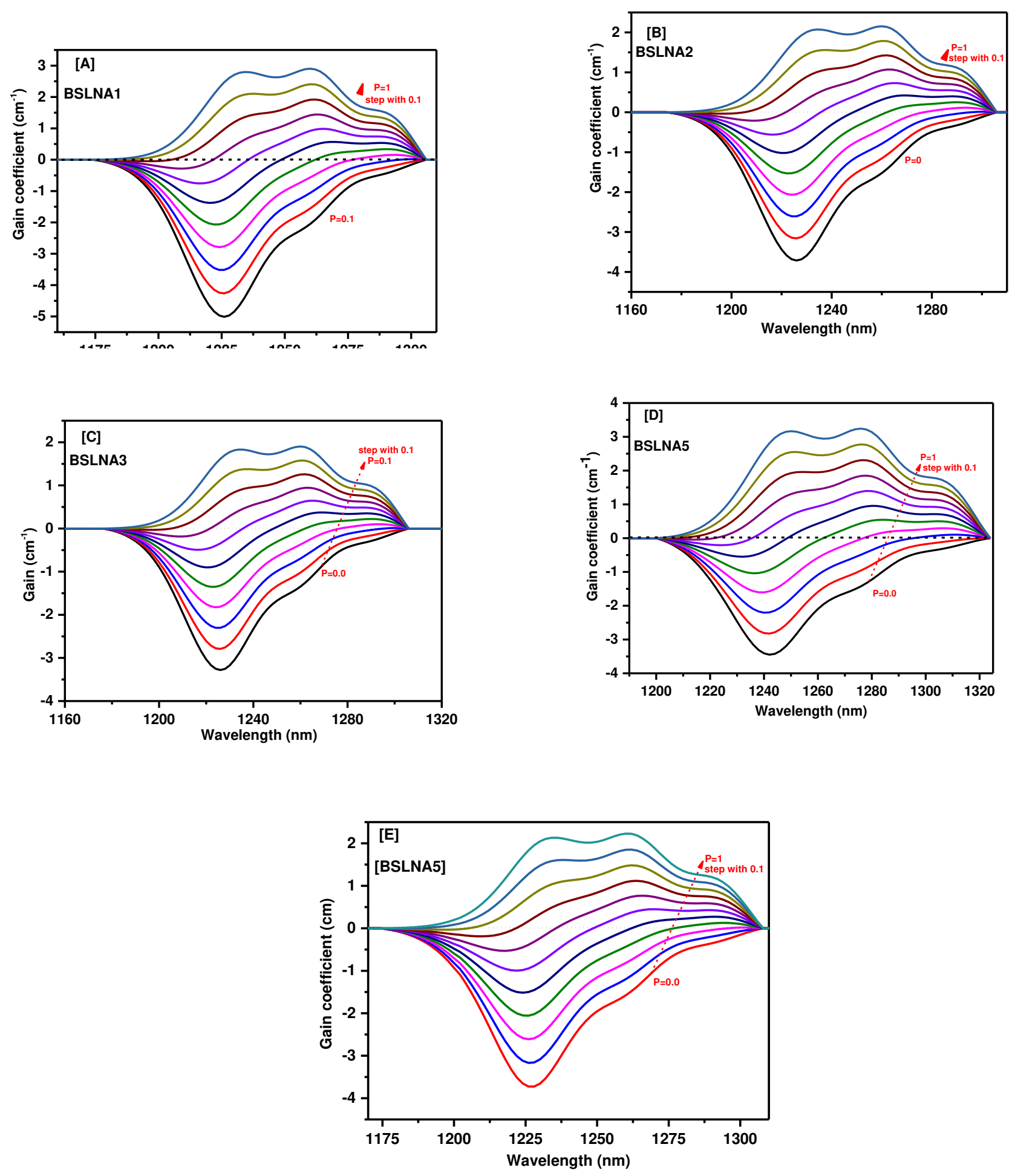

Figure 6: Gain coefficient for transitions of prepared glass samples doped with $\mathrm{Sm}_{2} \mathrm{O}_{3}$, [A] $\mathrm{Sm}^{3+} 100 \mathrm{ppm},[\mathrm{B}] \mathrm{Sm}^{3+}$ 200ppm, [C] $\mathrm{Sm}^{3+} 300 \mathrm{ppm},[\mathrm{D}] \mathrm{Sm}^{3+}$ 400ppm, [E] Sm${ }^{3+}$ $500 \mathrm{ppm}$. 


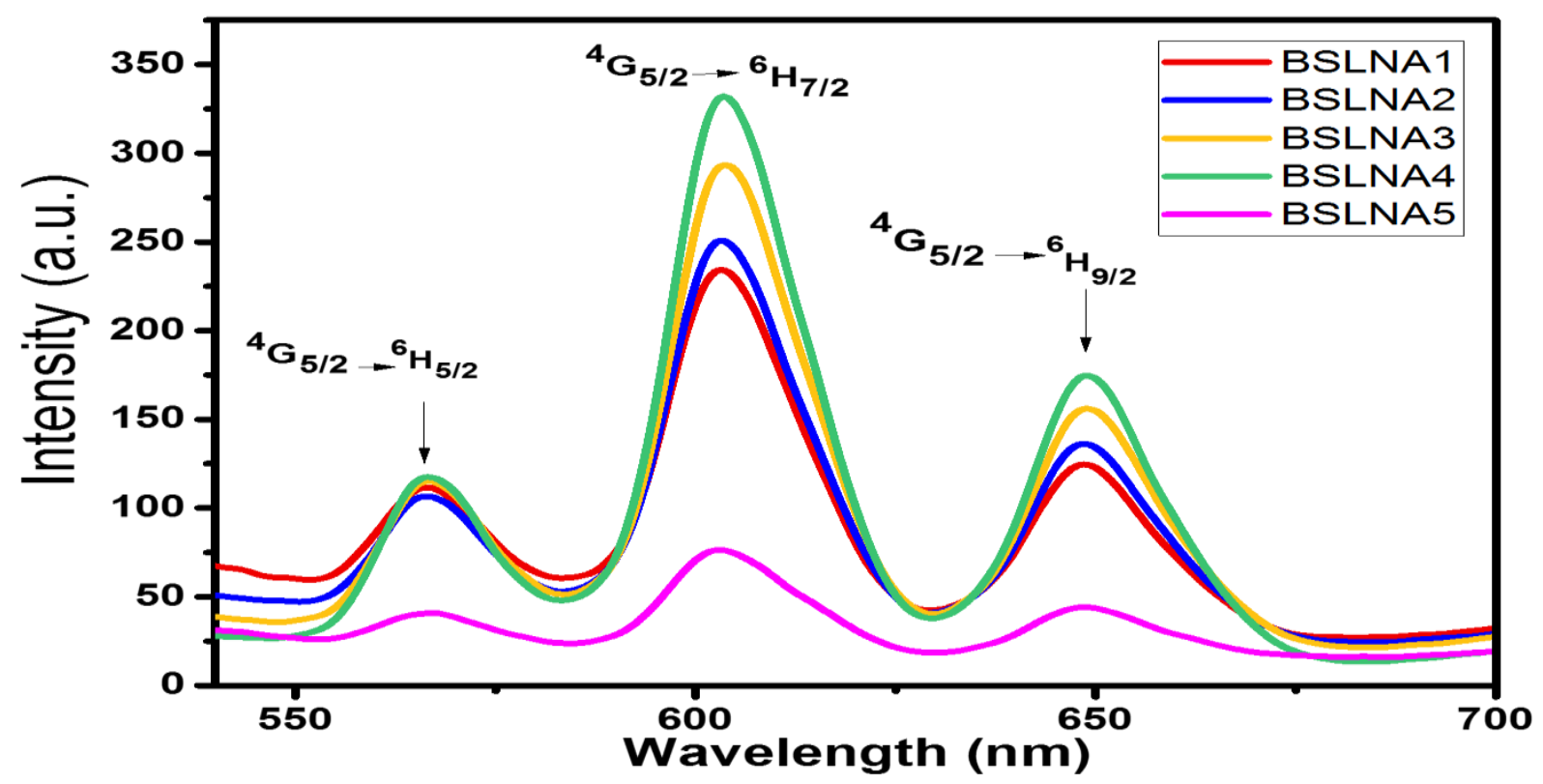

Figure 7: Emission spectra for the prepared glass samples doped with $\mathrm{Sm}_{2} \mathrm{O}_{3}$ under excitation wavelength $(402 \mathrm{~nm})$. 


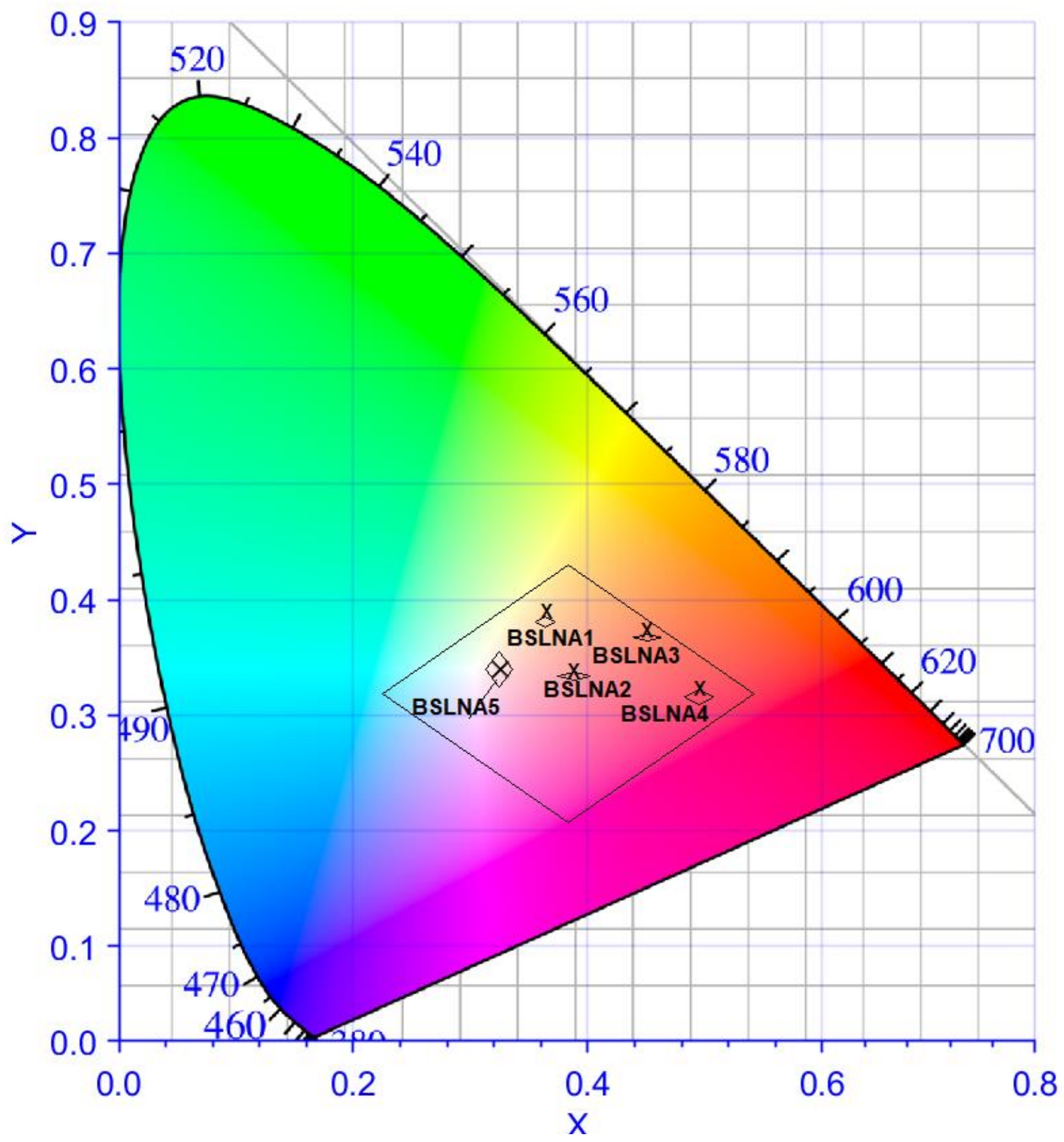

Figure 8: CIE-1931 chromaticity diagram for prepared glass BSLNA under excitation wavelength (402nm) 


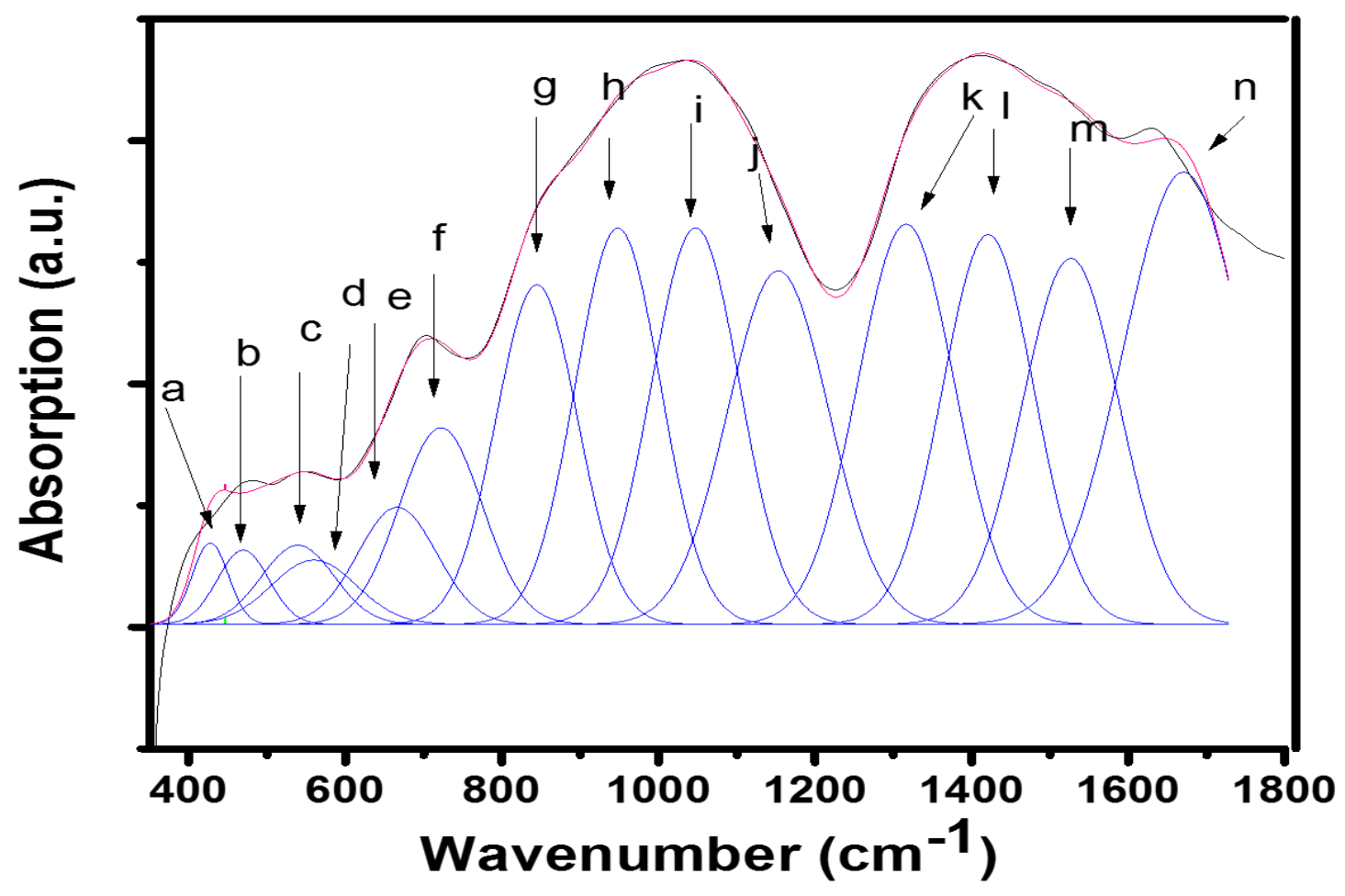

Figure 9: Deconvolution of FTIR spectra for BSLNA2 glass sample. 